\title{
Amyloid Biomarkers in Conformational Diseases at Face Value: A Systematic Review
}

\author{
Maria Fernanda Avila-Vazquez ${ }^{1,2}$, Nelly F. Altamirano-Bustamante ${ }^{3}$ and \\ Myriam M. Altamirano-Bustamante ${ }^{1, *}$ \\ 1 Unidad de Investigación en Enfermedades Metabólicas, Centro Médico Nacional Siglo XXI, IMSS, \\ Mexico City 06720, Mexico; feravilaibero@gmail.com \\ 2 Health Department, Universidad Iberoamericana, Mexico City 01219, Mexico \\ 3 Instituto Nacional de Pediatría, Mexico City 04530, Mexico; nellyab34@gmail.com \\ * Correspondence: myriamab@unam.mx; Tel.: +52-55-56276900 (ext. 22155)
}

Received: 15 September 2017; Accepted: 11 October 2017; Published: 29 December 2017

\begin{abstract}
Conformational diseases represent a new aspect of proteomic medicine where diagnostic and therapeutic paradigms are evolving. In this context, the early biomarkers for target cell failure (neurons, $\beta$-cells, etc.) represent a challenge to translational medicine and play a multidimensional role as biomarkers and potential therapeutic targets. This systematic review, which follows the PICO and Prisma methods, analyses this new-fangled multidimensionality, its strengths and limitations, and presents the future possibilities it opens up. The nuclear diagnosis methods are immunoassays: ELISA, immunodot, western blot, etc., while the therapeutic approach is focused on pharmaco- and molecular chaperones.
\end{abstract}

Keywords: biomarker; conformational diseases; Alzheimer's disease; diabetes mellitus; amyloid oligomers; cytotoxic oligomers

\section{Introduction}

How does evolution make proteins fold so fast? This is an unresolved problem at the crossroads between chemistry, physics, biology and proteomic medicine [1,2]. Sometimes proteins do not fold correctly and present folding errors (anomalous folding of non-native structures $(\mathrm{NN})$ ) [3-5]. Non-native structures interact with each other and form intra- or extracellular aggregates that may eventually form amyloid oligomers, protofilaments, amyloid fibers, leading to a resulting group of health problems [6-11]. Some examples are neurodegenerative diseases like Alzheimer's disease (AD) [12-15], and Parkinson's disease [16]. Another group are chronic diseases like cancer, cardiovascular diseases, and diabetes mellitus type 2 (DM2) [12,17]. Carrell grouped these diseases and called them conformational diseases (CDs) $[18,19]$. CDs have a common pathophysiological basis-an alteration at protein level, whether in size, shape, folding or conformation. Consequently, the resulting cytotoxicity produces a deficiency of functional proteins $[1,5-7,11,19,20]$.

The main component of amyloid deposits in $\mathrm{CDs}$, such as $\mathrm{AD}$, are oligomeric forms of amyloid- $\beta$ $(A \beta)$ such as $A \beta 1-40$ and $A \beta 1-42$, whereas in DM2 the deposits are from the amyloid polypeptide of the islets, also known as amylin [12,15,21]. Amylin is a hormone excreted and expressed synchronously with insulin in $\beta$-cells of the pancreas [8]. These amyloid forms have conformational polymorphism (dependant of the microenvironment) which produces different degrees of cytotoxicity [11,22].

The $\beta$-cross sheet is the structure that is formed by exposing the hydrophobic regions of soluble proteins giving rise to non-native structures. The NN structures interact with each other to form soluble oligomers that remain stable towards aggregation and oligomerization. This explains the entrenchment and deposition of protein aggregates in various organs, whereby tissue damage and organic dysfunction occurs $[5,6,11,23]$. 
Numerous studies show evidence of the interrelationship between CDs and obesity as a risk factor for DM2 and this, in turn, for AD [17,24]. In general, studies suggest that increased adipose tissue affects the body's response to insulin, leading to insulin resistance, impaired glucose metabolism, and faulty lipid homeostasis. This contributes greatly to heart disease since patients also develop hyperinsulinemia and hyperamylinemia which, in turn, leads to proteotoxicity and $\beta$-amyloid protein deposition [25]. A study by Zhao et al. with human pancreas samples proved the presence of oligomers in the pancreas through immunofluorescent staining [26]. AD, for example, affects approximately half of the population over 85 years of age [27]. Other theories state that such diseases may be due to a mutation [28], increased stress in the amyloid precursor protein (APP)/A $\beta$ metallic transport system, lifestyle [29], and promotion of ROS [30]. Another important factor is poor processing of the APP [31] influenced by $\beta$-proteins (BACE1) and $\gamma$-secretases [32], which promote protein aggregation. This information reveals the importance of amyloid deposition's importance in global health $[1,2,23]$.

For this reason, it is important to develop diagnostic techniques that can detect conformational diseases before their onset. It is believed that early diagnostics can be achieved through biomarkers even before CDs symptoms appear. A biomarker is an indicator of normal biological processes, pathological processes or pharmacological responses to a therapeutic intervention. In AD the APP and $\mathrm{A} \beta$-protein are the biomarkers that have tested the 'amyloid hypothesis' and have led to therapeutic interventions [33,34]. Biomarkers used for diagnosis are not only found in brain tissue, but also in peripheral tissues and fluids (i.e., cerebrospinal fluid (CSF)). However, these have limitations: oligomer stability [24], sample amount [27], assay number [35], sensitivity differences, and specificity differences. In addition, most of the diagnostic techniques require that the disease be at an advanced stage and often the diagnosis does not occur until the post-mortem stage with the presence of amyloid deposits in brain tissue [36].

The purpose of this review is to evaluate-following the Participants/Intervention/ Comparison/Outcome (PICO) and Preferred Reporting Items for Systematic Reviews and Meta-Analyses (PRISMA) methods-the literature related to immunoassay methods used to measure different amyloid biomarkers, with an emphasis in enzyme-linked immunosorbent assay (ELISA), immunodot, and western blot (Figures 1 and 2). One of the main objectives of this review is also to discuss new information in the latest findings about the aggregation of $\beta$-amyloid oligomers as well as the techniques for their diagnosis. Moreover, this review intends to include a broad spectrum of the status of amyloid hypothesis, diagnostic and treatment techniques. Given that Alzheimer's disease and diabetes mellitus are the costliest, both economically and socially, they are the most relevant diseases for this review. The following research questions based on the PICO method will be addressed: how are the different diagnostic methods for these conformational diseases related to $\beta$-amyloid oligomers and to what extent does their use as a multi-target technique provide a reasonable foundation for treating CDs? 


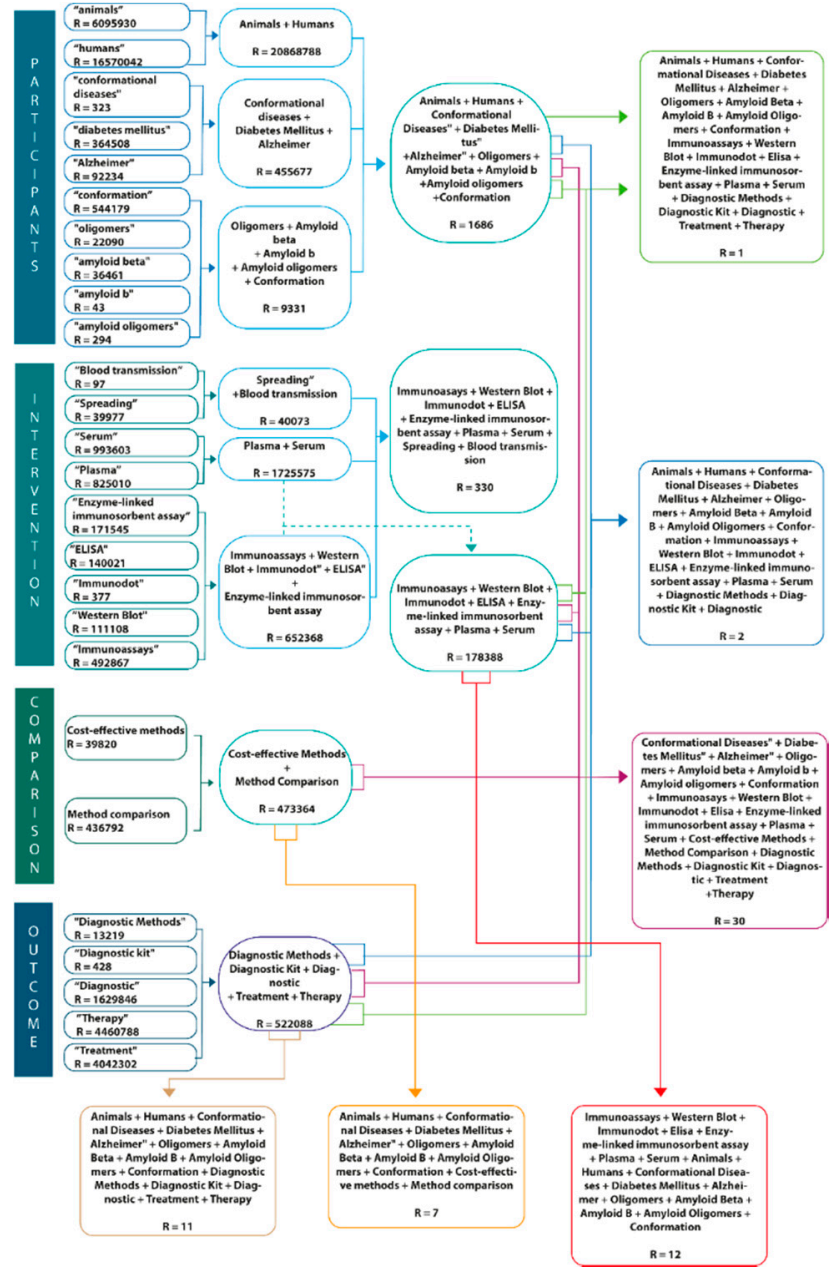

Figure 1. PICO approach for systematic review. P (participants): Humans, animals, Alzheimer, Diabetes Mellitus, conformational diseases, amyloid oligomers, amyloid- $\beta$, oligomers, conformation. I (intervention): immunoassays, western blot, immunodot, ELISA, Enzyme-linked immunosorbent assay, plasma, serum, spreading, blood transmission. C (comparison): Method comparison and cost-effective O (outcome): Diagnostic methods, diagnostic kit, diagnostic, treatment, therapy.

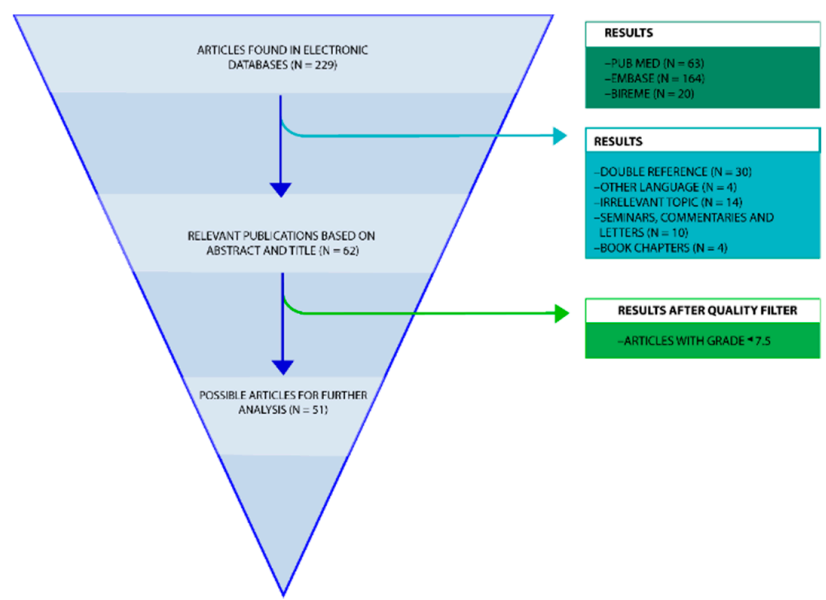

Figure 2. Flowchart review process. A PRISMA flowchart of the systematic review on the diagnostic methods for conformational diseases related to amyloid oligomers and the multi-target proteins using as potential drugs for CDs. 


\section{Results}

The review process began with 229 references retrieved from a variety of electronic databases (Figure 2). Of these 229 articles, 63 were retrieved from PubMed, 164 from Embase, and 20 from Bireme. However, not all of these articles were relevant to the research topic. For this reason, 192 articles were discarded. After that, articles with a double reference $(n=30)$; in another language $(n=4)$; whose topic was irrelevant to the review $(n=14)$; seminars, commentaries or letters $(n=10)$; and book chapters $(n=4)$ were discarded. This selection process left 51 articles of use to the review (Figure 2).

A second sifting was performed whereby only the articles that obtained over 75 points in the quality criteria were considered, the criteria used is similar to the one described by Van Mol [37] where the articles are ranked in relation to specific quality standards such as having a specified aim, a detailed description of methods, valid and reliable measuring, etc. Table 1 shows the result of each of the 51 articles that were considered. Following this process, 51 articles on immunoassays and $\beta$-amyloid oligomers were read in full text and further analysed (Figure 2), Table 1 list all 51 articles and their characteristics.

In general, the articles discussed the use of $\beta$-amyloid as a biomarker. In order to come to this conclusion, many studies performed a series of immunoassays, the most commonly used of which were ELISA and the western blot ones. However, a number of studies used immunodot, dot blot, homogeneous time-resolved fluorescence immunoassay (HTRF), and mass spectrometry (MS).

Most articles gave a detailed account of the type of immunoassay used, incubation time, number of washes, block solution used, pre-treatment or dilution, and the molecule analysed, all of which was relevant to the aim of this review which is to get to know the different methods of analysis. The most commonly analysed molecules throughout the articles were $\beta$-amyloid, APP, microtubule-associated protein tau (T-tau), amylin, HEWL oligomers, and antibodies.

Of the 51 articles taken into consideration at the third stage, 17 of them did not provide information on $\beta$-amyloid oligomers in human tissues and were actually reviews about specific topics: molecular differences between oligomers, the role of metal ions in $\beta$-amyloid aggregation and toxicity, and various treatments. It is also important to mention that articles found in this review are from different countries of origin; furthermore, it is unclear which country did more research on $\beta$-amyloid diagnostic methods, however, it can be stated that a slightly higher percentage of the articles came from Asian countries. The target populations were similar across the articles, most sampled humans with Alzheimer's disease CSF, human plasma, synthetic $\beta$-amyloid proteins, serum antibodies, and cerebral tissue with $\beta$-amyloid deposits. Interestingly, the other most commonly used samples were those of mice and rats, for instance, one of the samples mentioned were the brain samples of passively immunized $3 \times \mathrm{Tg}-\mathrm{AD}$ mice control and wild-type [38-40].

\subsection{The Biomarker Dilemma}

According to the amyloid hypothesis the stages of $\beta$-amyloid aggregation disrupt cell-to-cell communication and activate immune cells. These immune cells trigger inflammation, producing a continuous state of inflammation which ultimately leads to the destruction of the brain cells [13]. Because of this, the biomarkers proposed to do an early diagnosis of AD include central nervous system (CNS) A $\beta 42, A \beta 42 / A \beta 40$ ratio, soluble APP isoforms (sAPP $\alpha$ and sAPP $\beta$ ), T-tau, phosphorylated tau protein (P-tau), total tau (T-tau) protein, and neurofilament light (NFL) protein (Tables 1 and 2, Figures 3-5). 
Table 1. An overview of the included articles with the quality assessment.

\begin{tabular}{|c|c|c|c|c|c|}
\hline $\begin{array}{l}\text { First Author/Year of } \\
\text { Publication }\end{array}$ & Setting & Target Population and Sample Size & Target Molecule & Method & Quality $(\%$ \\
\hline Andreasen, et al. 1999 [39] & Sweden & $\begin{array}{l}16 \mathrm{MCI}-\mathrm{AD} \text { patients and } 15 \text { age-matched } \\
\text { controls }\end{array}$ & CSF A $\beta 42$ and CSF T-tau & $\begin{array}{l}\text { Longitudinal MCI-control } \\
\text { study/Elisa }\end{array}$ & 100 \\
\hline Arai, et al. $1995[41,42]$ & Japan & $\begin{array}{l}201 \text { CSF samples, } 87 \text { patients with } \\
\text { Alzheimer's disease (AD) and } 114 \text { patients } \\
\text { without neurological diseases }\end{array}$ & $\begin{array}{l}\text { Microtubule-associated protein tau } \\
\text { in CSF }\end{array}$ & Elisa & 75 \\
\hline Benedett, et al. 2015 [43] & Canada & $\begin{array}{l}417 \text { participants and } 174 \text { additional patients } \\
\text { with samples of CSF and P-Tau }\end{array}$ & $\mathrm{A} \beta$ & SUVR and PET & 87.5 \\
\hline Bittner, et al. 2015 [35] & Roche Diagnostics & 372 Human CSF with diagnosed AD & $\mathrm{A} \beta$ & $\begin{array}{l}\text { Elecsys } \beta \text {-amyloid assay (electro } \\
\text { chemiluminescence immunoassay) }\end{array}$ & 100 \\
\hline Blennow, et al. 2014 [27] & United States & Humans & $\begin{array}{l}\text { Cerebrospinal fluid biomarkers } \\
\text { such as B-amyloid, Tau and Tau } \\
\text { phosphorylated for } \\
\text { Alzheimer's detection }\end{array}$ & Article review & 75 \\
\hline Bouwman, et al. 2007 [44] & The Netherlands & $59 \mathrm{MCI}$ patients, 30 of them developed $\mathrm{AD}$ & CSF A $\beta 42$ and CSF T-tau & Longitudinal MCI study & 100 \\
\hline Breydo, et al. 2016 [24] & United States & Synthetic $A \beta$ & $\mathrm{A} \beta 40$ oligomers FOs and PFOs & $\begin{array}{l}\text { Raman, FTIR, CD spectroscopy and } \\
\text { Western Blot }\end{array}$ & 62.5 \\
\hline Brys, et al. 2007 [45] & United States & $\begin{array}{l}65 \mathrm{MCI} \text { patients, } 22 \text { of who later developed } \\
\mathrm{AD} \text { and } 21 \text { controls }\end{array}$ & $\begin{array}{l}\text { CSF A } \beta 42, A \beta 42 / \mathrm{A} \beta 40 \text { ratio, CSF } \\
\text { T-tau, CSF P-tau231 }\end{array}$ & Elisa and Innotest hTAU antigen kit & 100 \\
\hline Bush, et al. 1992 [31] & Germany & $\begin{array}{l}\text { Human platelets and plasma samples of } \\
\text { patients diagnosed with AD }\end{array}$ & APP & Western Blot and Immunodot & 87.5 \\
\hline Capule, et al. 2012 [36] & United States & $\begin{array}{l}\text { Synthetic } \beta \text {-amyloid proteins and AD A } \beta \\
\text { samples }\end{array}$ & Binding molecules to $A \beta$ & Elisa & 87.5 \\
\hline Chetri et al. 2015 [46] & India & Cultivated $\mathrm{A} \beta$ & Cultivated $\mathrm{A} \beta$ & Cloning of $A \beta$ with PCR & 62.5 \\
\hline Clarke, et al. 2000 [47] & United Kingdom & $\begin{array}{l}\text { Antibodies and } \mathrm{A} \beta \text { from humans and } \\
\text { rodents }\end{array}$ & $\mathrm{A} \beta$ & HTRF immunoassay & 87.5 \\
\hline Condello, et al. 2017 [48] & United States & Humans samples diagnosed with $\mathrm{AD}$ & $\mathrm{A} \beta$ and Tau aggregates & $\begin{array}{l}\text { Therapy and diagnostic options } \\
\text { revision for Alzheimer's }\end{array}$ & 87.5 \\
\hline Despa, et al. 2012 [25] & United States & $\begin{array}{l}\text { Left ventricular homogenates of obese, } \\
\text { non-obese and diabetic patients and rodents }\end{array}$ & Amylin & Western Blot/Dot Blot & 100 \\
\hline Doran, et al. 2015 [49] & United States & Antigen substitutes & $\begin{array}{l}\text { Antigens capable of identifying } \\
\text { sites of antibodies. Types: OBOC of } \\
\text { animals or humans control and } \\
\text { with disease of interest. }\end{array}$ & ELISA measurement & 75 \\
\hline
\end{tabular}


Table 1. Cont.

\begin{tabular}{|c|c|c|c|c|c|}
\hline $\begin{array}{l}\text { First Author/Year of } \\
\text { Publication }\end{array}$ & Setting & Target Population and Sample Size & Target Molecule & Method & Quality (\%) \\
\hline Giacomelli, et al. 2017 [33] & Italy & $\begin{array}{l}\text { Human post-mortem brain, plasma, } \\
\text { platelets, CSF, RBC, samples and AD mice }\end{array}$ & $\mathrm{A} \beta$, tau and a-syn & Bibliographic analysis & 75 \\
\hline Gustafson, et al. 2007 [50] & Sweden & 55 cognitively healthy women & CSF A $\beta 42$ & $\begin{array}{l}\text { Longitudinal cohort study and } \\
\text { Sandwich ELISA (Innotest } \\
\text { hTAU-Ag) }\end{array}$ & 100 \\
\hline Hansson, et al. 2006 [51] & Sweden & $137 \mathrm{MCI}$ patients, 57 of whom developed $\mathrm{AD}$ & $\begin{array}{l}\text { CSF A } \beta 42 \text {, high CSF T-tau, and } \\
\text { CSF P-tau181 }\end{array}$ & Luminex xMAP technology & 100 \\
\hline Hansson, et al. 2007 [52] & Sweden & $137 \mathrm{MCI}$ patients, 57 of whom developed $\mathrm{AD}$ & $\mathrm{A} \beta 42 / \mathrm{A} \beta 40$ ratio & Elisa & 100 \\
\hline Hampel, et al. 2004 [53] & Germany & $\begin{array}{l}52 \mathrm{MCI} \text { patients, } 93 \mathrm{AD} \text { patients and } 10 \\
\text { controls }\end{array}$ & CSF A $\beta 42$ and CSF T-tau & Elisa & 100 \\
\hline Herukka, et al. 2005 [54] & Finland & $\begin{array}{l}78 \mathrm{MCI} \text { patients, } 23 \text { of whom developed } \mathrm{AD} \text {, } \\
46 \text { controls }\end{array}$ & $\begin{array}{l}\text { CSF A } 342, \text { CSF T-tau, and CSF } \\
\text { P-tau181 }\end{array}$ & Elisa & 100 \\
\hline Herukka, et al. 2007 [55] & Finland & $\begin{array}{l}79 \text { MCI patients, } 33 \text { of whom developed AD, } \\
60 \text { controls }\end{array}$ & $\begin{array}{l}\text { CSF A } \beta 42, \text { CSF T-tau, and CSF } \\
\text { P-tau181 }\end{array}$ & PCR and Elisa & 100 \\
\hline Iwatsubo. 1998 [28] & Japan & $\begin{array}{l}6 \text { patients with Beta APP } 717,44 \text { patients } \\
\text { with sporadic AD, } 22 \text { controls of } \\
\text { neurological diseases and } 15 \text { controls } \\
\text { without neurological disease }\end{array}$ & $\begin{array}{l}\text { C-terminus of } \beta \text {-amyloid } 42 \text { and } \\
\beta \text {-amyloid } 40\end{array}$ & Two-site Elisa & 87.5 \\
\hline Janssen, et al. 2015 [56] & Belgium & $\begin{array}{l}\text { Aggregated } \beta \text {-amyloid oligomers from } \\
\text { mouse brain and human CSF }\end{array}$ & $\beta$-amyloid & $\begin{array}{l}\text { Samples exposed to a pretreatment } \\
\text { with TFA, FA and HFIP with } \\
\text { ELISA/Western Blot (SDS-PAGE) }\end{array}$ & 75 \\
\hline Jayamani, et al. 2014 [57] & India & Synthetic insulin and Gallic acid & $\begin{array}{l}\text { Insulin in vitro and } A \beta \text { fibril } \\
\text { formation }\end{array}$ & $\begin{array}{l}\text { UV-Visible spectroscopy, ThT } \\
\text { fluorescence spectroscopy, CD, } \\
\text { Fourier-transformed infrared } \\
\text { (FTIR) spectroscopy, and fibril } \\
\text { morphology using atomic force } \\
\text { microscopy (AFM) }\end{array}$ & 87.5 \\
\hline Kepp, et al. 2017 [29] & Denmark & Patients with Alzheimer's disease & Metal ions and $\beta$-amyloid & Bibliographic review & 75 \\
\hline Khan, et al. 2017 [58] & United States & Human $A \beta 40$ synthetic peptides & $\mathrm{A} \beta 40$ & $\begin{array}{l}\text { Dichroism and Fluorescence } \\
\text { emission spectroscopy }\end{array}$ & 62.5 \\
\hline Kim, et al. 2014 [59] & Korea & Human plasma & Synthetic A $\beta 40$ & $\begin{array}{l}\text { SRM-MS and antibody-free } \\
\text { spectrometry }\end{array}$ & 87.5 \\
\hline Klaver, et al. 2011 [60] & United States & $\begin{array}{l}328 \text { Serum antibodies with } \mathrm{AD}, \mathrm{MCI} \text { or ICU } \\
\text { patients }\end{array}$ & $\beta$-amyloid and antibodies & Western Blot and Elisa & 87.5 \\
\hline
\end{tabular}


Table 1. Cont.

\begin{tabular}{|c|c|c|c|c|c|}
\hline $\begin{array}{l}\text { First Author/Year of } \\
\text { Publication }\end{array}$ & Setting & Target Population and Sample Size & Target Molecule & Method & Quality $(\%$ \\
\hline Kuo, et al. 2017 [61] & Taiwan & Hen lysozyme & Amyloid fibrils and erythrosine B & $\begin{array}{l}\text { Molecular docking and molecular } \\
\text { dynamics simulations }\end{array}$ & 62.5 \\
\hline Li, et al. 2007 [62] & United States & 43 controls, 4 of whom developed MCI & $\mathrm{T}$-tau/A $\beta 42$ ratio & Luminex reagents & 100 \\
\hline Mangione, et al. 2016 [63] & Italy & Chaperone Hsp60 & $\mathrm{A} \beta 40$ & CD, TEM, AFM and SEC & 75 \\
\hline $\begin{array}{l}\text { Mattsson, et al. } \\
2009[40,64]\end{array}$ & Sweden & $\begin{array}{l}750 \mathrm{MCI} \text { patients, } 271 \text { of whom } \\
\text { developed } \mathrm{AD}\end{array}$ & $\begin{array}{l}\text { CSF A } 342, \text { CSF T-tau, and CSF } \\
\text { P-tau181 }\end{array}$ & Sandwich Elisa & 100 \\
\hline Murakami. 2014 [65] & Japan & Alzheimer's disease patients & $A \beta$ oligomers & Immunotherapy & 87.5 \\
\hline Niedowicz, et al. 2012 [66] & United States & $\begin{array}{l}23 \text { controls age } 87 \text { years average, } 22 \text { patients } \\
\text { with Alzheimer's average age } 85\end{array}$ & $\mathrm{~A} \beta$ & Elisa & 75 \\
\hline $\begin{array}{l}\text { Ordóñez-Gutiérrez, et al. } \\
2016 \text { [32] }\end{array}$ & Spain & $\begin{array}{l}\text { ImmunoPEGliposomes with } \beta \text {-amyloid in } \\
\text { brain cells and in vitro phagocytes in mice } \\
\text { aged } 16 \text { months and } 10 \text { months of age }\end{array}$ & $\beta$-amyloid peptides & Elisa and Western Blot & 87.5 \\
\hline Permanne, et al. 1995 [67] & France & 17 elderly with AD and no AD & $\mathrm{A} \beta$ & Dot-blot and Western Blot & 100 \\
\hline Plagg, et al. 2015 [68] & Austria & $\begin{array}{l}\text { Platelets of mice with hypercholesterolemia } \\
\text { and } 43 \text { humans with and } 30 \text { controls }\end{array}$ & APP & Elisa and Western Blot & 87.5 \\
\hline Read, et al. 1992 [34] & The Netherlands & 4 CSF samples from patients with dementia & APP & Elisa & 75 \\
\hline Ringman, et al. 2008 [70] & United States & $\begin{array}{l}\text { CSF biomarker results were compared in } \\
7 \text { asymptomatic carriers of familial AD } \\
\text { (FAD)-associated mutations and four } \\
\text { non-carriers }\end{array}$ & $\begin{array}{l}\text { CSF A } \beta 42, \mathrm{~A} \beta 42 / \mathrm{A} \beta 40 \text { ratio, CSF } \\
\text { T-tau, and CSF P-tau181 }\end{array}$ & Elisa & 100 \\
\hline Rogeberg, et al. 2015 [71] & Norway & $\begin{array}{l}19 \text { of the Alzheimer's CSF samples and } \\
19 \text { CSF healthy controls }\end{array}$ & $\mathrm{A} \beta$ & $\begin{array}{l}\text { Mass spectrometry (MS), sandwich } \\
\text { Elisa, Immunoprecipitation }\end{array}$ & 87.5 \\
\hline Roqanian, et al. 2017 [72] & Iran & Cerebral rat samples & HEWL Oligomers & $\begin{array}{l}\text { ThT fluorescent assay, and Nile red } \\
\text { binding assay }\end{array}$ & 100 \\
\hline Ruiz, et al. 2015 [73] & Mexico & Aggregated $\beta$-amyloid fibrils & $\mathrm{A} \beta$ fibrils & Surface tension and DLS & 75 \\
\hline Salvadores, et al. 2014 [74] & United States & $\begin{array}{l}50 \text { samples of CSF patients with } \mathrm{AD}+30 \\
\text { healthy control patients and } 39 \text { other } \\
\text { neurological diseases }\end{array}$ & $A \beta$ oligomers $/ \operatorname{PrP}$ & PMCA & 87.5 \\
\hline Sharoar, et al. 2013 [75] & Bangladesh & $\begin{array}{l}\text { Samples of human neuroblastoma cells } \\
\text { in vitro }\end{array}$ & $\mathrm{A} \beta$ & $\begin{array}{l}\text { Th-T assay, CD spectroscopy, } \\
\text { Immunoblot and Dot blot }\end{array}$ & 75 \\
\hline Shaw, et al. 2009 [76] & United States & $196 \mathrm{MCI}$ patients, 37 of whom developed AD & $\begin{array}{l}\text { CSF A } \beta 42, \text { CSF T-tau, and CSF } \\
\text { P-tau181 }\end{array}$ & $\begin{array}{l}\text { Multiplex immunoassay; xMAP } \\
\text { Luminex }\end{array}$ & 100 \\
\hline
\end{tabular}


Table 1. Cont.

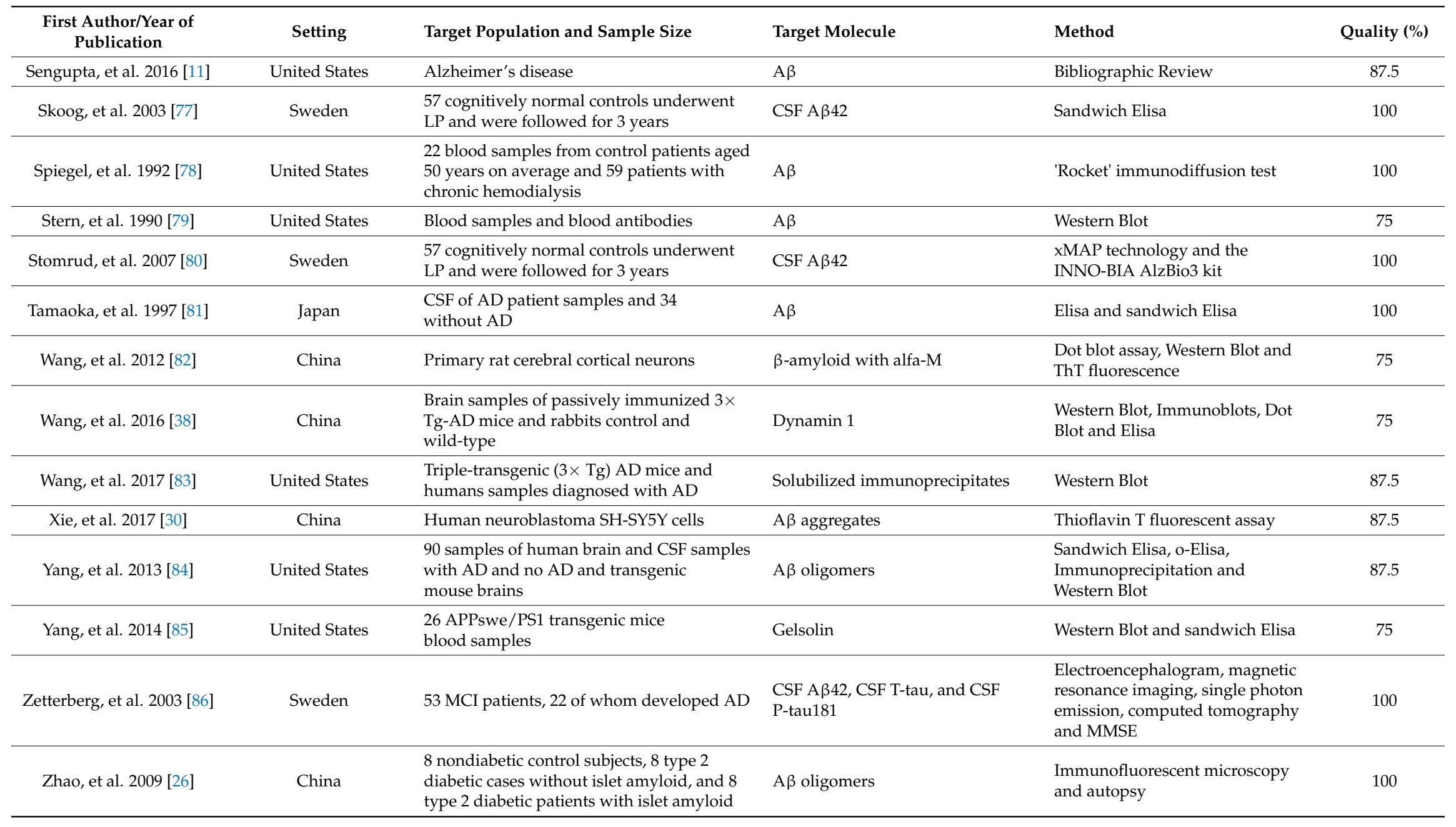


Table 2. An overview of the included articles with the study characteristics.

\begin{tabular}{|c|c|c|c|c|c|c|c|c|}
\hline Reference & Setting & Target Molecule & Method of Analysis & Target Population & Clinical Data & $\begin{array}{l}\text { Sensibility and } \\
\text { Specificity }\end{array}$ & Pretreatment & Antibodies \\
\hline $\begin{array}{l}\text { Andreasen, et al. } \\
1999 \text { [39] }\end{array}$ & Sweden & $\begin{array}{l}\text { CSF A } \beta 42 \text { and CSF } \\
\text { T-tau }\end{array}$ & Elisa & $\begin{array}{l}16 \text { MCI-AD patients, } \\
15 \text { age-matched controls }\end{array}$ & $\begin{array}{l}\text { Low CSF A } \beta 42 \text {, high CSF T-tau } \\
\text { associated with AD }\end{array}$ & Sensibility: $88 \%$ & IA & $\begin{array}{l}\text {-Antibodies: } 21 F 12 \text { and 3D6 } \\
\text {-Kit: Innotest } \beta \text {-amyloid } \\
\text { (1-40) Innogenetics }\end{array}$ \\
\hline $\begin{array}{l}\text { Arai, et al. } 1996 \\
{[41,42]}\end{array}$ & Japan & $\begin{array}{l}\text { Microtubule-associated } \\
\text { protein tau in CSF }\end{array}$ & $\begin{array}{l}\text { Sandwich Elisa and } \\
\text { Western Blot }\end{array}$ & $\begin{array}{l}114 \text { patients non- } \mathrm{AD} \\
\text { neurological diseases, } \\
22 \text { normal subjects }\end{array}$ & $\begin{array}{l}\text { CSF tau increased in AD patients } \\
\text { compared with non-AD } \\
\text { neurological disease }\end{array}$ & $\begin{array}{l}\text { Sensitivity and } \\
\text { specificity } \\
\text { missing }\end{array}$ & IA & -Not mentioned \\
\hline $\begin{array}{l}\text { Bittner, et al. } \\
2015 \text { [35] }\end{array}$ & Roche Diagnostics & $A \beta$ & Elecsys $\beta$-amyloid assay & 372 Human CSF & $\begin{array}{l}\text { Elecsys } \beta \text {-amyloid } 42 \text { has high analytical } \\
\text { performance that improves } \\
\text { biomarker-based AD diagnosis }\end{array}$ & $\begin{array}{l}\text { Sensitivity and } \\
\text { specificity } \\
\text { missing }\end{array}$ & IA & \\
\hline $\begin{array}{l}\text { Bouwman, et al. } \\
2007[44]\end{array}$ & The Netherlands & $\begin{array}{l}\text { CSF A } 442 \text { and CSF } \\
\text { T-tau }\end{array}$ & $\begin{array}{l}\text { Innotest } \beta \text {-amyloid1-42 } \\
\text { and Innotest hTau-Ag }\end{array}$ & $\begin{array}{l}59 \mathrm{MCI} \text { patients, } 30 \text { of } \\
\text { whom developed } \mathrm{AD}\end{array}$ & $\begin{array}{l}\text { Patients with abnormal values at } \\
\text { baseline had higher risk of } \\
\text { developing AD. }\end{array}$ & $\begin{array}{l}\text { Sensitivity and } \\
\text { specificity } \\
\text { missing. }\end{array}$ & $\begin{array}{l}\text { Pretreatment } \\
\text { missing. }\end{array}$ & \\
\hline $\begin{array}{l}\text { Brys, et al. } \\
2007[45]\end{array}$ & United States & $\begin{array}{l}\text { CSF A } \beta 42, \\
\text { A } \beta 42 / \mathrm{A} \beta 40 \text { ratio, } \\
\text { CSF T-tau, CSF } \\
\text { P-tau231 }\end{array}$ & $\begin{array}{l}\text { Innotest hTAU antigen } \\
\text { kit; sandwich Elisa for } \\
\text { P-tau231 }\end{array}$ & $\begin{array}{l}65 \mathrm{MCI} \text { patients, } 22 \text { of } \\
\text { whom developed } \mathrm{AD} \text {, } \\
21 \text { controls }\end{array}$ & $\begin{array}{l}\text { All biomarkers were statistically } \\
\text { significant predictors of the decline from } \\
\text { MCI to AD with P-tau } 231 \text { and T-tau the } \\
\text { strongest univariate predictors. }\end{array}$ & $\begin{array}{l}\text { Sensitivity } \\
68-86 \%, \\
\text { specificity } \\
60-91 \%\end{array}$ & $\begin{array}{l}\text { Pretreatment } \\
\text { missing. }\end{array}$ & $\begin{array}{l}\text {-Antibody: Monoclonal } \\
\text { antibody 6E10 } \\
\text {-Kit: INNOTEST hTAU } \\
\text { antigen kit (Innogenetics®, } \\
\text { Gent, Belgium). }\end{array}$ \\
\hline $\begin{array}{l}\text { Bush, et al. } \\
1992[31]\end{array}$ & Germany & APP & Western Blot; Immunodot & $\begin{array}{l}\text { Human platelets, human } \\
\text { plasma of AD cases }\end{array}$ & $\begin{array}{l}\beta \text {-amyloid deposition may result in } \\
\text { failure of APP }\end{array}$ & $\begin{array}{l}\text { Sensitivity and } \\
\text { specificity } \\
\text { missing }\end{array}$ & $\begin{array}{l}\text { Pretreatment } \\
\text { missing }\end{array}$ & \\
\hline $\begin{array}{l}\text { Capule, et al. } \\
2012[36]\end{array}$ & United States & $\begin{array}{l}\text { Binding molecules to } \\
\mathrm{A} \beta\end{array}$ & Elisa & $\begin{array}{l}96 \text { ELISA plates of } \\
\text { Synthetic beta amyloid } \\
\text { proteins and AD A } \beta \\
\text { samples }\end{array}$ & $\begin{array}{l}\text { Protocol overcomes many limitations of } \\
\text { previously reported spectroscopic or } \\
\text { radioactivity assays and facilitate the } \\
\text { screening and evaluation of a more } \\
\text { structurally diverse set of } \\
\text { amyloid-targeting agents }\end{array}$ & $\begin{array}{l}\text { Sensitivity and } \\
\text { specificity } \\
\text { missing. }\end{array}$ & Air plasma & $\begin{array}{l}\text {-Antibody: 6E10 } \\
\text {-Kit: not mentioned }\end{array}$ \\
\hline $\begin{array}{l}\text { Clarke, et al. } \\
2000[47]\end{array}$ & United Kingdom & $A \beta$ & $\begin{array}{l}\text { Homogeneous } \\
\text { time-resolved } \\
\text { fluorescence (HTRF) } \\
\text { immunoassay }\end{array}$ & $\begin{array}{l}\text { Synthetic } \beta \text {-amyloid } \\
\text { proteins and antibodies } \\
\text { from humans and } \\
\text { rodents }\end{array}$ & $\begin{array}{l}\text { This assay allows specific, direct } \\
\text { quantitation of } A \beta \text { peptides in cell } \\
\text { culture medium, plasma, cerebrospinal } \\
\text { fluid and brain tissue extracts. }\end{array}$ & $\begin{array}{l}\text { Sensitivity and } \\
\text { specificity } \\
\text { missing }\end{array}$ & $\begin{array}{l}\text { Pretreatment } \\
\text { missing }\end{array}$ & \\
\hline $\begin{array}{l}\text { Despa, et al. } \\
2012[25]\end{array}$ & United States & Amylin & Western Blot/Dot Blot & $\begin{array}{l}\text { Left ventricular } \\
\text { homogenates of humans } \\
\text { and rodents with DM2 } \\
\text { and controls }\end{array}$ & $\begin{array}{l}\text { Hyperamylinemia promotes amylin } \\
\text { deposition in the heart, causing } \\
\text { alterations of cardiac myocyte structure } \\
\text { and function. }\end{array}$ & $\begin{array}{l}\text { Sensitivity and } \\
\text { specificity } \\
\text { missing. }\end{array}$ & $\begin{array}{l}\text { Pretreatment } \\
\text { missing. }\end{array}$ & \\
\hline $\begin{array}{l}\text { Giacomelli, et al. } \\
\quad 2017 \text { [33] }\end{array}$ & Italy & $\mathrm{A} \beta$, tau and a-syn & $\begin{array}{l}\text { Congo red } \\
\text { Fluorescent microscopy, } \\
\text { Thioflavin-T, Elisa, } \\
\text { SPECT, PET and } \\
\text { Western Blot }\end{array}$ & $\begin{array}{l}\text { Human post-mortem } \\
\text { brain, plasma, platelets, } \\
\text { CSF, RBC, samples and } \\
\text { AD mice }\end{array}$ & $\begin{array}{l}\text { Biomarkers establishment and } \\
\text { assessment is important for diagnosis } \\
\text { and therapeutic options }\end{array}$ & IA & IA & \\
\hline $\begin{array}{l}\text { Gustafson, et al. } \\
2007 \text { [50] }\end{array}$ & Sweden & CSF A 342 & $\begin{array}{l}\text { Sandwich ELISA and } \\
\text { Innotest hTAU-Ag }\end{array}$ & $\begin{array}{l}55 \text { cognitively healthy } \\
\text { women }\end{array}$ & $\begin{array}{l}\text { Low levels of CSF A } \beta 42 \text { predicted } \\
\text { cognitive decline. }\end{array}$ & $\begin{array}{l}\text { Sensitivity and } \\
\text { specificity } \\
\text { missing. }\end{array}$ & $\begin{array}{l}\text { Pretreatment } \\
\text { missing. }\end{array}$ & $\begin{array}{l}\text {-Antibody: not mentioned } \\
\text {-Kit: Innotest } \beta \text {-amyloid } \\
\text { 1-42; Innogenetics, } \\
\text { Zwijndrecht, Belgium }\end{array}$ \\
\hline
\end{tabular}


Table 2. Cont

\begin{tabular}{|c|c|c|c|c|c|c|c|c|}
\hline Reference & Setting & Target Molecule & Method of Analysis & Target Population & Clinical Data & $\begin{array}{l}\text { Sensibility and } \\
\text { Specificity }\end{array}$ & Pretreatment & Antibodies \\
\hline $\begin{array}{l}\text { Hansson, et al. } \\
\quad 2006 \text { [51] }\end{array}$ & Sweden & $\begin{array}{l}\text { CSF A } \beta 42 \text {, high CSF } \\
\text { T-tau, and CSF } \\
\text { P-tau181 }\end{array}$ & $\begin{array}{l}\text { Luminex xMAP } \\
\text { technology }\end{array}$ & $\begin{array}{l}137 \text { MCI patients, } 57 \text { of } \\
\text { whom developed } \mathrm{AD}\end{array}$ & $\begin{array}{l}\text { Concentrations of T-tau, P-tau181, and } \\
\text { A } \beta 42 \text { in CSF are strongly associated } \\
\text { with future development of Alzheimer's } \\
\text { disease in patients with MCI. }\end{array}$ & $\begin{array}{l}\text { Sensitivity } 95 \% \text {, } \\
\text { specificity } 83 \% \text {, } \\
\text { PPV } 81 \% \text {, } \\
\text { NPV } 96 \%\end{array}$ & IA & \\
\hline $\begin{array}{l}\text { Hansson, et al. } \\
\quad 2007 \text { [52] }\end{array}$ & Sweden & $\mathrm{A} \beta 42 / \mathrm{A} \beta 40$ ratio & Elisa & $\begin{array}{l}137 \text { MCI patients, } 57 \text { of } \\
\text { whom developed } \mathrm{AD}\end{array}$ & $\begin{array}{l}\text { Amyloid precursor protein metabolism } \\
\text { is disturbed in early sporadic } \mathrm{AD} \text { and } \\
\text { points to the usefulness of the } \\
\mathrm{A} \beta 42 / \mathrm{A} \beta 40 \text { ratio as a predictive } \\
\text { biomarker for } \mathrm{AD} \text {. }\end{array}$ & $\begin{array}{l}\text { Sensitivity } 87 \% \text {, } \\
\text { specificity } 78 \%\end{array}$ & $\begin{array}{l}\text { Pretreatment } \\
\text { missing. }\end{array}$ & $\begin{array}{l}\text {-Antibodies: W02 (epitope } \\
\text { AB 5-8), detection } \\
\text { anti-bodies G2-10 for A } 340 \\
\text { and G2-13 for A } 342 \\
\text {-Kit: The Genetics } \\
\text { Company }\end{array}$ \\
\hline $\begin{array}{l}\text { Hampel, et al. } \\
\quad 2004 \text { [53] }\end{array}$ & Germany & $\begin{array}{l}\text { CSF A } 442 \text { and CSF } \\
\text { T-tau }\end{array}$ & Elisa & $\begin{array}{l}52 \mathrm{MCI} \text { patients, } 93 \mathrm{AD} \\
\text { patients and } 10 \text { controls }\end{array}$ & $\begin{array}{l}\text { CSF tau and A } \beta 1-42 \text { may be useful } \\
\text { biomarkers in the early identification of } \\
\mathrm{AD} \text { in MCI subjects. }\end{array}$ & $\begin{array}{l}\text { Sensitivity } \\
59-83 \% \text {, } \\
\text { specificity } \\
90-100 \%\end{array}$ & $\begin{array}{l}\text { Pretreatment } \\
\text { missing. }\end{array}$ & $\begin{array}{l}\text {-Antibody: not mentioned } \\
\text {-Kit: Innotest } \beta \text {-amyloid } \\
\text { 1-42 and Innotest } \\
\text { TTAU-Ag, Innogenetics, } \\
\text { Zwjindrecht, Belgium }\end{array}$ \\
\hline $\begin{array}{l}\text { Herukka, et al. } \\
\quad 2005[54]\end{array}$ & Finland & $\begin{array}{l}\text { CSF A } \beta 42, \text { CSF T-tau, } \\
\text { and CSF P-tau181 }\end{array}$ & Elisa & $\begin{array}{l}78 \mathrm{MCI} \text { patients, } 23 \text { of } \\
\text { whom developed } \mathrm{AD} \text {, } \\
46 \text { controls }\end{array}$ & $\begin{array}{l}\text { The most predictive assay for } \mathrm{AD} \\
\text { among the patients with MCI was the } \\
\text { combination of } A \beta 42 \text { and P-tau. }\end{array}$ & $\begin{array}{l}\text { Sensitivity } 91 \% \text {, } \\
\text { specificity } 56 \%\end{array}$ & $\begin{array}{l}\text { Pretreatment } \\
\text { missing. }\end{array}$ & $\begin{array}{l}\text {-Antibody: not mentioned } \\
\text {-Kit: Innogenetics, Ghent, } \\
\text { Bel-gium }\end{array}$ \\
\hline $\begin{array}{l}\text { Herukka, et al. } \\
\quad 2007 \text { [55] }\end{array}$ & Finland & $\begin{array}{l}\text { CSF A } \beta 42, \text { CSF T-tau, } \\
\text { and CSF P-tau181 }\end{array}$ & PCR and Elisa & $\begin{array}{l}79 \text { MCI patients, } 33 \text { of } \\
\text { whom developed } \mathrm{AD}, \\
60 \text { controls }\end{array}$ & $\begin{array}{l}\text { Low levels of CSF } A \beta 42 \text { predicted } \\
\text { progression to AD. }\end{array}$ & $\begin{array}{l}\text { Sensitivity and } \\
\text { specificity } \\
\text { missing. }\end{array}$ & $\begin{array}{l}\text { Pretreatment } \\
\text { missing. }\end{array}$ & $\begin{array}{l}\text {-Antibody: not mentioned } \\
\text {-Kit: Innogenetics, Ghent, } \\
\text { Belgium }\end{array}$ \\
\hline $\begin{array}{l}\text { Iwatsubo, } \\
1998[28]\end{array}$ & Japan & $\begin{array}{l}\text { C-terminus of } \mathrm{A} \beta 42 \\
\text { and } \beta \text {-amyloid } 40\end{array}$ & Two-site Elisa & $\begin{array}{l}6 \text { patients with Beta APP } \\
717,44 \text { patients with } \\
\text { sporadic } \mathrm{AD}, 22 \text { controls } \\
\text { of neurological diseases } \\
\text { and } 15 \text { controls without } \\
\text { neurological disease }\end{array}$ & $\begin{array}{l}\text { Levels of } \mathrm{A} \beta \text {, especially those of } \mathrm{A} \beta 42 \\
\text { are altered in the plasma of patients } \\
\text { with } \mathrm{AD} \text {, including carriers of AP717 } \\
\text { mutation that is linked to familial AD. }\end{array}$ & $\begin{array}{l}\text { Sensitivity and } \\
\text { specificity } \\
\text { missing. }\end{array}$ & $\begin{array}{l}\text { Pretreatment } \\
\text { missing. }\end{array}$ & \\
\hline $\begin{array}{l}\text { Janssen, et al. } \\
2015 \text { [56] }\end{array}$ & Belgium & $\beta$-amyloid & Elisa and Western Blot & $\begin{array}{l}\text { Aggregated } \beta \text {-amyloid } \\
\text { oligomers from mouse } \\
\text { brain and human CSF }\end{array}$ & $\begin{array}{l}\text { Chemically pre-treating samples to } \\
\text { disaggregate oligomers can (partially) } \\
\text { recover the signal loss. }\end{array}$ & $\begin{array}{l}7.81 \text { and } \\
500 \mathrm{pg} / \mathrm{mL}\end{array}$ & $\begin{array}{l}\text { Trifluoroacetic } \\
\text { acid, formic } \\
\text { acid or HFIP }\end{array}$ & $\begin{array}{l}\text {-Antibody: 6E10 } \\
\text {-Kit: Human Amyloid } \beta \\
\text { (1-x) Assay kit (IBL } \\
\text { International) }\end{array}$ \\
\hline $\begin{array}{l}\text { Jayamani, et al. } \\
\text { 2014 [57] }\end{array}$ & India & Insulin in vitro & $\begin{array}{l}\text { UV-Visible spectroscopy, } \\
\text { ThT fluorescence } \\
\text { spectroscopy, CD, } \\
\text { Fourier-transformed } \\
\text { infrared (FTIR) } \\
\text { spectroscopy, and fibril } \\
\text { morphology using atomic } \\
\text { force microscopy (AFM) }\end{array}$ & $\begin{array}{l}\text { Synthetic insulin and } \\
\text { Gallic acid }\end{array}$ & $\begin{array}{l}\text { Gallic acid can inhibit insulin } A \beta \text { fibril } \\
\text { formation in vitro }\end{array}$ & $\begin{array}{l}\text { Sensitivity and } \\
\text { specificity } \\
\text { missing. }\end{array}$ & Gallic acid & \\
\hline $\begin{array}{l}\text { Kepp, et al. } \\
2017 \text { [29] }\end{array}$ & Denmark & $\begin{array}{l}\text { Metal ions and } \\
\beta \text {-amyloid }\end{array}$ & IA & $\begin{array}{l}\text { Patients with } \\
\text { Alzheimer's disease }\end{array}$ & $\begin{array}{l}\text { The metal- } \mathrm{A} \beta \text { interactions have } \\
\text { elements of both gain of toxic function. } \\
\text { Possible treatments for } \beta \text {-Amyloid } \\
\text { accumulation: metal chelation, } \\
\text { treatment with anti-oxidant and } \\
\text { anti-inflammatory molecules. }\end{array}$ & IA & IA & \\
\hline
\end{tabular}


Table 2. Cont

\begin{tabular}{|c|c|c|c|c|c|c|c|c|}
\hline Reference & Setting & Target Molecule & Method of Analysis & Target Population & Clinical Data & $\begin{array}{l}\text { Sensibility and } \\
\text { Specificity }\end{array}$ & Pretreatment & Antibodies \\
\hline $\begin{array}{l}\text { Kim, et al. } \\
2014 \text { [59] }\end{array}$ & Korea & $\beta$-amyloid & $\begin{array}{l}\text { Mass spectrometry } \\
\text { (MS)-based quantification }\end{array}$ & Human plasma & $\begin{array}{l}\beta \text {-amyloid can be measured regardless } \\
\text { of the conformational status of the } \\
\text { biomarker }\end{array}$ & $\begin{array}{l}\text { Sensitivity and } \\
\text { specificity } \\
\text { missing. }\end{array}$ & Trypsin & \\
\hline $\begin{array}{l}\text { Klaver, et al. } \\
2011[60]\end{array}$ & United States & $\begin{array}{l}\beta \text {-amyloid and } \\
\text { antibodies }\end{array}$ & Western Blot and Elisa & $\begin{array}{l}328 \text { Serum antibodies } \\
\text { with AD patients, } \\
\text { subjects with mild } \\
\text { cognitive impairment, } \\
\text { and aged non-cognitively } \\
\text { impaired individuals }\end{array}$ & $\begin{array}{l}\text { Hypothesis that reduced levels of anti- } \\
\mathrm{A} \beta \text { antibodies might contribute to } \mathrm{AD}^{\prime} \mathrm{s} \\
\text { pathogenesis not proven. }\end{array}$ & $\begin{array}{l}\text { Sensitivity and } \\
\text { specificity } \\
\text { missing. }\end{array}$ & $\begin{array}{l}\text { Pretreatment } \\
\text { missing }\end{array}$ & $\begin{array}{l}\text {-Antibody: } 6 \mathrm{E} 10 \text { anti-A } \beta \\
\text { antibody } \\
\text {-Kit: not mentioned }\end{array}$ \\
\hline Li, et al. 2007 [62] & United States & $\mathrm{T}$-tau $/ \mathrm{A} \beta 42$ ratio & Luminex reagents & $\begin{array}{l}43 \text { controls, } 4 \text { of whom } \\
\text { developed MCI }\end{array}$ & $\begin{array}{l}\text { Individuals with high ratio had higher } \\
\text { APOE } \varepsilon 4 \text { allele frequency and higher } \\
\text { risk of progression to MCI }\end{array}$ & $\begin{array}{l}\text { High sensitivity } \\
\text { and specificity }\end{array}$ & IA & \\
\hline $\begin{array}{l}\text { Mangione, et al. } \\
2016 \text { [63] }\end{array}$ & Italy & $\mathrm{A} \beta 40$ & CD, TEM, AFM and SEC & Chaperone Hsp60 & Hsp60 inhibits $A \beta$ & $\begin{array}{l}\text { Sensitivity and } \\
\text { specificity } \\
\text { missing }\end{array}$ & IA & \\
\hline $\begin{array}{l}\text { Mattsson, et al. } \\
2009[40,64]\end{array}$ & Sweden & $\begin{array}{l}\text { CSF A } \beta 42, \text { CSF T-tau, } \\
\text { and CSF P-tau181 }\end{array}$ & Sandwich Elisa & $\begin{array}{l}750 \text { MCI patients, } 271 \text { of } \\
\text { whom developed } \mathrm{AD}\end{array}$ & $\begin{array}{l}\text { CSFA 42, T-tau, and P-tauidentify } \\
\text { incipient AD with good accuracy }\end{array}$ & $\begin{array}{l}\text { Sensitivity } 83 \% \text {, } \\
\text { specificity } 88 \% \\
\text { for MCI-AD } \\
\text { versus controls; } \\
\text { sensitivity } 83 \% \text {, } \\
\text { specificity } 72 \% \\
\text { for MCI-AD } \\
\text { versus all MCI } \\
\text { cases }\end{array}$ & $\begin{array}{l}\text { Pretreatment } \\
\text { missing }\end{array}$ & $\begin{array}{l}\text {-Innotest } \\
\text { Phospho-Tau[181P] } \\
\text {-Innotest-amyloid (1-42) }\end{array}$ \\
\hline $\begin{array}{l}\text { Murakami. } \\
2014[65]\end{array}$ & Japan & $A \beta$ oligomers & Immunotherapy & $\begin{array}{l}\text { Alzheimer's disease } \\
\text { patients }\end{array}$ & $\begin{array}{l}\text { Immunotherapy using anti- } \mathrm{A} \beta \text { anti- } \\
\text { body is a possible approach for } \mathrm{AD} \\
\text { treatment }\end{array}$ & IA & IA & \\
\hline $\begin{array}{l}\text { Niedowicz, et al. } \\
2012 \text { [66] }\end{array}$ & United States & $\mathrm{A} \beta$ & Elisa & $\begin{array}{l}\text { Samples of patients with } \\
\mathrm{AD}(22) \text { and controls }(23) \\
\text { and four different brain } \\
\text { regions }\end{array}$ & $\begin{array}{l}\text { Postmortem PiB binding is useful in } \\
\text { distinguishing AD from control cases, } \\
\text { SDS-soluble Ab measured by standard } \\
\text { immunoassay was better. }\end{array}$ & $\begin{array}{l}\text { Sensitivity of } \\
100 \% \text { and a } \\
\text { specificity of } \\
95.7 \%\end{array}$ & PBS buffer & $\begin{array}{l}\text {-Antibody: Ab9 (human } \\
\text { sequence Ab1-16), } \\
\text { Ab13.1.1, 12F4 (Covance, } \\
\text { Princeton, NJ) y 4G8 } \\
\text {-Kit: not mentioned }\end{array}$ \\
\hline $\begin{array}{l}\text { Ordóñez-Gutiérrez, } \\
\text { et al. 2016 [32] }\end{array}$ & Spain & $A \beta$ & Elisa and Western Blot & $\begin{array}{l}\text { ImmunoPEGliposomes } \\
\text { with } \beta \text {-amyloid in brain } \\
\text { cells and in vitro } \\
\text { phagocytes in mice aged } \\
16 \text { months and } 10 \text { months } \\
\text { of age }\end{array}$ & $\begin{array}{l}\text { Treatment lowered the ratio of } \\
\text { phosphorylated Tau to total Tau. } \\
\text { Therapeutic efficacy of } \\
\text { immunoliposome treatment was } \\
\text { superior to free monoclonal antibody } \\
\text { administration. }\end{array}$ & $\begin{array}{l}\text { Sensitivity and } \\
\text { specificity } \\
\text { missing. }\end{array}$ & $\begin{array}{l}\text { Pretreatment } \\
\text { missing }\end{array}$ & $\begin{array}{l}\text {-Antibody: 6E10 anti-A } \beta \\
\text {-Kit: Qubits Protein Assay } \\
\text { Kit. }\end{array}$ \\
\hline $\begin{array}{c}\text { Permanne, et al. } \\
1995[67]\end{array}$ & France & $\mathrm{A} \beta$ & $\begin{array}{l}\text { Dot-blot and Western } \\
\text { Blot }\end{array}$ & $\begin{array}{l}17 \text { elderly with } \mathrm{AD} \text { and } \\
\text { no } \mathrm{AD}\end{array}$ & $\begin{array}{l}\text { Method detects amyloid-associated } \\
\text { components such as apolipoprotein E. }\end{array}$ & High sensitivity & Formic acid & \\
\hline $\begin{array}{l}\text { Plagg, et al. } \\
2015 \text { [68] }\end{array}$ & Austria & APP & Elisa and Western Blot & $\begin{array}{l}73 \text { patients with } \mathrm{AD}(43) \\
\text { and controls (30) }\end{array}$ & $\begin{array}{l}\text { Decreased platelet APP isoforms in AD } \\
\text { patients, APP beta altered in humans } \\
\text { and mice with AD, lower EGF levels in } \\
\text { human AD patients. }\end{array}$ & $\begin{array}{l}\text { Highly } \\
\text { sensitive. }\end{array}$ & $\begin{array}{l}\text { Pretreatment } \\
\text { missing }\end{array}$ & $\begin{array}{l}\text {-Antibody: biotinylated } \\
\text { antibody CD62P } \\
\text {-Kit: sAPPb-w (highly } \\
\text { sensitive) Assay Kit-IBL }\end{array}$ \\
\hline
\end{tabular}


Table 2. Cont

\begin{tabular}{|c|c|c|c|c|c|c|c|c|}
\hline Reference & Setting & Target Molecule & Method of Analysis & Target Population & Clinical Data & $\begin{array}{l}\text { Sensibility and } \\
\text { Specificity }\end{array}$ & Pretreatment & Antibodies \\
\hline $\begin{array}{l}\text { Read, et al. } \\
1992 \text { [34] }\end{array}$ & The Netherlands & APP & Elisa & $\begin{array}{l}4 \text { ventricular and lumbar } \\
\text { CSF samples ventricular } \\
\text { with AD }\end{array}$ & $\begin{array}{l}\text { Low APP levels as a diagnostic marker } \\
\text { for AD }\end{array}$ & $\begin{array}{l}\text { Sensitivity and } \\
\text { specificity } \\
\text { missing. }\end{array}$ & $\begin{array}{l}\text { Pretreatment } \\
\text { missing }\end{array}$ & $\begin{array}{l}\text {-Antibody: not mentioned } \\
\text {-Kit: not mentioned }\end{array}$ \\
\hline $\begin{array}{l}\text { Riemenschneider, } \\
\text { et al. } 2002[69]\end{array}$ & Germany & $\begin{array}{l}\text { CSF A } \beta 42 \text { and CSF } \\
\text { T-tau }\end{array}$ & Elisa & $\begin{array}{l}28 \text { MCI patients, } 10 \text { of } \\
\text { whom developed } \mathrm{AD}\end{array}$ & $\begin{array}{l}\text { Results indicate that altered tau and } \\
\text { A } \beta 42 \text { concentration can be detected in } \\
\text { MCI patients but with pathological } \\
\text { changes of AD }\end{array}$ & $\begin{array}{l}\text { Sensitivity } 90 \% \text {, } \\
\text { specificity } 90 \%\end{array}$ & $\begin{array}{l}\text { Pretreatment } \\
\text { missing }\end{array}$ & $\begin{array}{l}\text {-Antibody: not metioned } \\
\text {-Kit: Innogenetics, } \\
\text { Zwjindrecht, Belgium }\end{array}$ \\
\hline $\begin{array}{l}\text { Ringman, et al. } \\
2008 \text { [70] }\end{array}$ & United States & $\begin{array}{l}\text { CSF A } \beta 42, \\
\text { A } \beta 42 / \mathrm{A} \beta 40 \text { ratio, } \\
\text { CSF T-tau, and CSF } \\
\text { P-tau181 }\end{array}$ & Elisa & $\begin{array}{l}\text { CSF biomarker results } \\
\text { were compared in } 7 \\
\text { asymptomatic carriers of } \\
\text { familial AD } \\
\text { (FAD)-associated } \\
\text { mutations and four } \\
\text { non-carriers }\end{array}$ & $\begin{array}{l}\text { Asymptomatic FAD mutation carriers } \\
\text { had abnormal CSF biomarkers already } \\
\text { in their } 30 \mathrm{~s}\end{array}$ & $\begin{array}{l}\text { Sensitivity and } \\
\text { specificity } \\
\text { missing }\end{array}$ & $\begin{array}{l}\text { Pretreatment } \\
\text { missing }\end{array}$ & $\begin{array}{l}\text {-Antibody: Takeda } \\
\text { BAN50/BA27 and } \\
\text { BNT77/BC05 antibodies } \\
\text {-Kit: not mentioned }\end{array}$ \\
\hline $\begin{array}{l}\text { Rogeberg, et al. } \\
\quad 2015[71]\end{array}$ & Norway & $A \beta$ & $\begin{array}{l}\text { Mass spectrometry (MS), } \\
\text { sandwich Elisa, } \\
\text { Immunoprecipitation }\end{array}$ & $\begin{array}{l}19 \text { samples of CSF of AD } \\
\text { patients and } 9 \text { control } \\
\text { healthy patients }\end{array}$ & $\begin{array}{l}\text { Method could be used to assess } \\
\text { disease-modifying therapies directed at } \\
\mathrm{A} \beta \text { production or degradation. }\end{array}$ & $\begin{array}{l}\text { Sensitivity and } \\
\text { specificity } \\
\text { missing }\end{array}$ & $\begin{array}{l}\text { Pretreatment } \\
\text { missing }\end{array}$ & $\begin{array}{l}\text {-Antibodies: 4G8, 6E10, } \\
\text { and a } 12 \mathrm{EF} 325 \text { mid-domair } \\
\text { antibody } \\
\text {-Kit: Innotest hTau Ag, } \\
\text { Phospho-Tau 181P, } \\
\beta \text {-amyloid (1-42) }\end{array}$ \\
\hline $\begin{array}{l}\text { Roqanian, et al. } \\
\quad 2017 \text { [72] }\end{array}$ & Iran & HEWL Oligomers & $\begin{array}{l}\text { ThT fluorescent assay, } \\
\text { Nile red binding assay }\end{array}$ & Cerebral rat samples & $\begin{array}{l}\text { Polyphenols frequently interacting with } \\
\text { amyloid aggregates may serve as a } \\
\text { therapeutic approach for } \\
\text { amyloid-related diseases. }\end{array}$ & $\begin{array}{l}\text { Sensitivity and } \\
\text { specificity } \\
\text { missing. }\end{array}$ & IA & \\
\hline $\begin{array}{l}\text { Ruiz, et al. } \\
2015 \text { [73] }\end{array}$ & Mexico & $A \beta$ fibrils & DLS & $\begin{array}{l}\text { Aggregated } \beta \text {-amyloid } \\
\text { fibrils }\end{array}$ & IA & $\begin{array}{l}\text { Sensitivity and } \\
\text { specificity } \\
\text { missing. }\end{array}$ & IA & \\
\hline $\begin{array}{l}\text { Salvadores, et al. } \\
\quad 2014[74]\end{array}$ & Italy & $\mathrm{A} \beta$ oligomers $/ \operatorname{PrP}$ & PMCA & $\begin{array}{l}50 \text { samples of CSF } \\
\text { patients with } \mathrm{AD}+30 \\
\text { healthy control patients }+ \\
39 \text { other neurological } \\
\text { diseases }\end{array}$ & $\begin{array}{l}\text { AD patients from control individuals } \\
\text { affected by a variety of other } \\
\text { neurodegenerative disorders or } \\
\text { nondegenerative neurological diseases }\end{array}$ & $\begin{array}{l}\text { Sensitivity of } \\
90 \% \text { and } \\
\text { specificity of } \\
92 \%\end{array}$ & IA & \\
\hline $\begin{array}{l}\text { Shaw, et al. } \\
2009 \text { [76] }\end{array}$ & United States & $\begin{array}{l}\text { CSF A } \beta 42, \text { CSF T-tau, } \\
\text { and CSF P-tau181 }\end{array}$ & $\begin{array}{l}\text { Multiplex immunoassay } \\
\text { and xMAP Luminex }\end{array}$ & $\begin{array}{l}196 \mathrm{MCI} \text { patients, } 37 \text { of } \\
\text { whom developed AD }\end{array}$ & $\begin{array}{l}\text { CSF A } A 1-42 \text { was the most sensitive } \\
\text { biomarker for AD in the autopsy cohort } \\
\text { of CSF }\end{array}$ & $\begin{array}{l}\text { CSF } \\
\text { T-tau/A } \beta 42 \text { had } \\
\text { a sensitivity of } \\
89 \% \text { for MCI } \\
\text { cases with } \\
\text { progression to } \\
\text { AD }\end{array}$ & $\begin{array}{l}\text { Pretreatment } \\
\text { missing. }\end{array}$ & \\
\hline $\begin{array}{l}\text { Skoog, et al. } \\
2003 \text { [77] }\end{array}$ & Sweden & CSF A $\beta 42$ & Sandwich Elisa & $\begin{array}{l}35 \text { non-demented } 85 \text { year } \\
\text { olds underwent LP and } \\
\text { were followed for } 3 \text { years }\end{array}$ & $\begin{array}{l}\text { Low levels of CSF } A \beta 42 \text { predicted } \\
\text { progression to dementia }\end{array}$ & $\begin{array}{l}\text { Sensitivity and } \\
\text { specificity } \\
\text { missing. }\end{array}$ & $\begin{array}{l}\text { Pretreatment } \\
\text { missing. }\end{array}$ & $\begin{array}{l}\text {-Antibody: 3D6 } \\
\text {-Kit: not mentioned }\end{array}$ \\
\hline
\end{tabular}


Table 2. Cont

\begin{tabular}{|c|c|c|c|c|c|c|c|c|}
\hline Reference & Setting & Target Molecule & Method of Analysis & Target Population & Clinical Data & $\begin{array}{l}\text { Sensibility and } \\
\text { Specificity }\end{array}$ & Pretreatment & Antibodies \\
\hline $\begin{array}{l}\text { Stomrud, et al. } \\
2007[80]\end{array}$ & Sweden & CSF A $\beta 42$ & xMAP technology & $\begin{array}{l}57 \text { cognitively normal } \\
\text { controls underwent LP } \\
\text { and were followed for } \\
3 \text { years }\end{array}$ & $\begin{array}{l}\text { Low levels of CSF } A \beta 42 \text { predicted } \\
\text { cognitive decline }\end{array}$ & $\begin{array}{l}\text { Sensitivity of } \\
71.4 \% \text { and a } \\
\text { specificity of } \\
75.7 \%\end{array}$ & IA & \\
\hline $\begin{array}{l}\text { Tamaoka, et al. } \\
\quad 1997 \text { [81] }\end{array}$ & Japan & $A \beta$ & Elisa and sandwich Elisa & $\begin{array}{l}\text { CSF of AD patient } \\
\text { samples and } 34 \\
\text { without } \mathrm{AD}\end{array}$ & $\begin{array}{l}\text { CSF-A } \beta 42(43) \text { could reflect increased } \\
\text { amino terminal truncations and/or } \\
\text { modifications of } A \beta 42(43) \text { in } A D \text { brains }\end{array}$ & $\begin{array}{l}\text { Sensitivity and } \\
\text { specificity } \\
\text { missing. }\end{array}$ & $\begin{array}{l}\text { Pretreatment } \\
\text { missing. }\end{array}$ & $\begin{array}{l}\text {-Antibodies: BNT77 } \\
\text { (anti-A } \beta 11-28 \text { ) and BAN50 } \\
\text { (anti-A } \beta 1-16 \text { ) } \\
\text {-Kit: not mentioned }\end{array}$ \\
\hline $\begin{array}{l}\text { Wang, et al. } \\
2012 \text { [82] }\end{array}$ & China & $\begin{array}{l}\beta \text {-amyloid with } \\
\text { alfa-M }\end{array}$ & $\begin{array}{l}\text { Dot blot assay, Western } \\
\text { Blot and ThT fluorescence }\end{array}$ & $\begin{array}{l}\text { Primary rat cerebral } \\
\text { cortical neurons }\end{array}$ & $\begin{array}{l}\mathrm{a}-\mathrm{M} \text { could be a great potential candidate } \\
\text { for } \mathrm{AD} \text { treatment }\end{array}$ & $\begin{array}{l}\text { Sensitivity and } \\
\text { specificity } \\
\text { missing. }\end{array}$ & $\begin{array}{l}\text { Pretreatment } \\
\text { missing. }\end{array}$ & \\
\hline $\begin{array}{l}\text { Wang, et al. } \\
2016 \text { [38] }\end{array}$ & China & Dynamin 1 & $\begin{array}{l}\text { Western Blot, } \\
\text { Immunoblot, Dot Blot } \\
\text { and Elisa }\end{array}$ & $\begin{array}{l}\text { Brain samples of } \\
\text { passively immunized } 3 \times \\
\text { Tg-AD mice control and } \\
\text { wild-type }\end{array}$ & $\begin{array}{l}\text { Passive immunization with } \mathrm{A} \beta 42 \\
\text { possible treatment }\end{array}$ & $\begin{array}{l}\text { Sensitivity and } \\
\text { specificity } \\
\text { missing. }\end{array}$ & $\begin{array}{l}\text { Pretreatment } \\
\text { missing. }\end{array}$ & $\begin{array}{l}\text {-Antibody: not mentioned } \\
\text {-Kit: Biosource ELISA kits } \\
\text { (Invitrogen, Carlsbad, CA, } \\
\text { USA) }\end{array}$ \\
\hline $\begin{array}{l}\text { Wang, et al. } \\
2017 \text { [83] }\end{array}$ & United States & $\begin{array}{l}\text { Solubilized } \\
\text { immunoprecipitates }\end{array}$ & Western Blot & $\begin{array}{l}\text { Triple-transgenic }(3 \times \mathrm{Tg}) \\
\text { AD mice }\end{array}$ & $\begin{array}{l}\text { PTI- } 125 \text { is the first therapeutic candidate } \\
\text { for AD }\end{array}$ & $\begin{array}{l}\text { Sensitivity and } \\
\text { specificity } \\
\text { missing. }\end{array}$ & $\begin{array}{l}\text { Pretreatment } \\
\text { missing. }\end{array}$ & \\
\hline $\begin{array}{l}\text { Xie, et al. } \\
2017[30]\end{array}$ & China & $A \beta$ aggregates & $\begin{array}{l}\text { Thioflavin T fluorescent } \\
\text { assay }\end{array}$ & $\begin{array}{l}\text { Human neuroblastoma } \\
\text { SH-SY5Y cells }\end{array}$ & $\begin{array}{l}\text { A-HSA worked as a bifunctional } \\
\text { inhibitor against } \mathrm{Cu}^{+2} \text {-mediated A } \beta 42 \\
\text { aggregation and cytotoxicity under a } \\
\text { mildly acidic condition }\end{array}$ & $\begin{array}{l}\text { Sensitivity and } \\
\text { specificity } \\
\text { missing. }\end{array}$ & $\begin{array}{l}\text { Acid } \\
\text { conditions }\end{array}$ & \\
\hline $\begin{array}{l}\text { Yang, et al. } \\
2013 \text { [84] }\end{array}$ & United States & $A \beta$ oligomers & $\begin{array}{l}\text { Sandwich Elisa, } \\
\text { Immunoprecipitation and } \\
\text { Western Blot }\end{array}$ & $\begin{array}{l}\text { Human brain samples } \\
\text { with } \mathrm{AD} \text { and no } \mathrm{AD} \text { and } \\
\text { transgenic mouse brains }\end{array}$ & $\begin{array}{l}\text { New o-ELISAs method for biomarker } \\
\text { AD }\end{array}$ & $\begin{array}{l}\text { Sensitivity and } \\
\text { specificity } \\
\text { missing. }\end{array}$ & IA & $\begin{array}{l}\text {-Antibodies: (MAb) } 266 \text { to } \\
\text { the Aßmidregion (residues } \\
\text { 13-28) or MAb, 3D6 (to } \\
\text { residues 1-5), Mab 4G8 (to } \\
\text { residues 18-22; D6 or } \\
\text { MAbNAB61, MAbs266 and } \\
\text { 3D6 were kindly provided } \\
\text { by Elan, plc } \\
\text {-Kit: not mentioned }\end{array}$ \\
\hline $\begin{array}{l}\text { Yang, et al. } \\
2014 \text { [85] }\end{array}$ & United States & Gelsolin & $\begin{array}{l}\text { Western Blot and } \\
\text { sandwich Elisa }\end{array}$ & $\begin{array}{l}26 \text { APPswe/PS1 } \\
\text { transgenic mice blood } \\
\text { samples }\end{array}$ & Gelsolin decreases $A \beta$ & $\begin{array}{l}\text { Sensitivity and } \\
\text { specificity } \\
\text { missing. }\end{array}$ & TSA & $\begin{array}{l}\text {-Antibody: 6E10 } \\
\text {-Kit: not mentioned }\end{array}$ \\
\hline $\begin{array}{l}\text { Zetterberg, et al. } \\
\quad 2003 \text { [86] }\end{array}$ & Sweden & $\begin{array}{l}\text { CSF A } \beta 42, \text { CSF T-tau, } \\
\text { and CSF P-tau181 }\end{array}$ & $\begin{array}{l}\text { Electroencephalogram, } \\
\text { MRI, single photon } \\
\text { emission, computed } \\
\text { tomography and MMSE }\end{array}$ & $\begin{array}{l}53 \text { MCI patients, } 22 \text { of } \\
\text { whom developed } \mathrm{AD}\end{array}$ & Missing information. & $\begin{array}{l}\text { Sensitivity } 68 \% \text {, } \\
\text { specificity } 97 \% \text {, } \\
\text { PPV } 94 \% \text {, NPV } \\
81 \% \\
\end{array}$ & IA & \\
\hline $\begin{array}{l}\text { Zhao, et al. } \\
2009 \text { [26] }\end{array}$ & China & $A \beta$ oligomers & $\begin{array}{l}\text { Immunofluorescent } \\
\text { microscopy }\end{array}$ & $\begin{array}{l}8 \text { nondiabetic control } \\
\text { subjects, } 8 \text { type } 2 \text { diabetic } \\
\text { cases without islet } \\
\text { amyloid, and } 8 \text { type } 2 \\
\text { diabetic patients with } \\
\text { islet amyloid }\end{array}$ & $\begin{array}{l}\text { Large oligomers were spatially localized } \\
\text { adjacent to amyloid fibrils and were } \\
\text { associated with apoptosis }\end{array}$ & $\begin{array}{l}\text { Sensitivity and } \\
\text { specificity } \\
\text { missing. }\end{array}$ & IA & \\
\hline
\end{tabular}




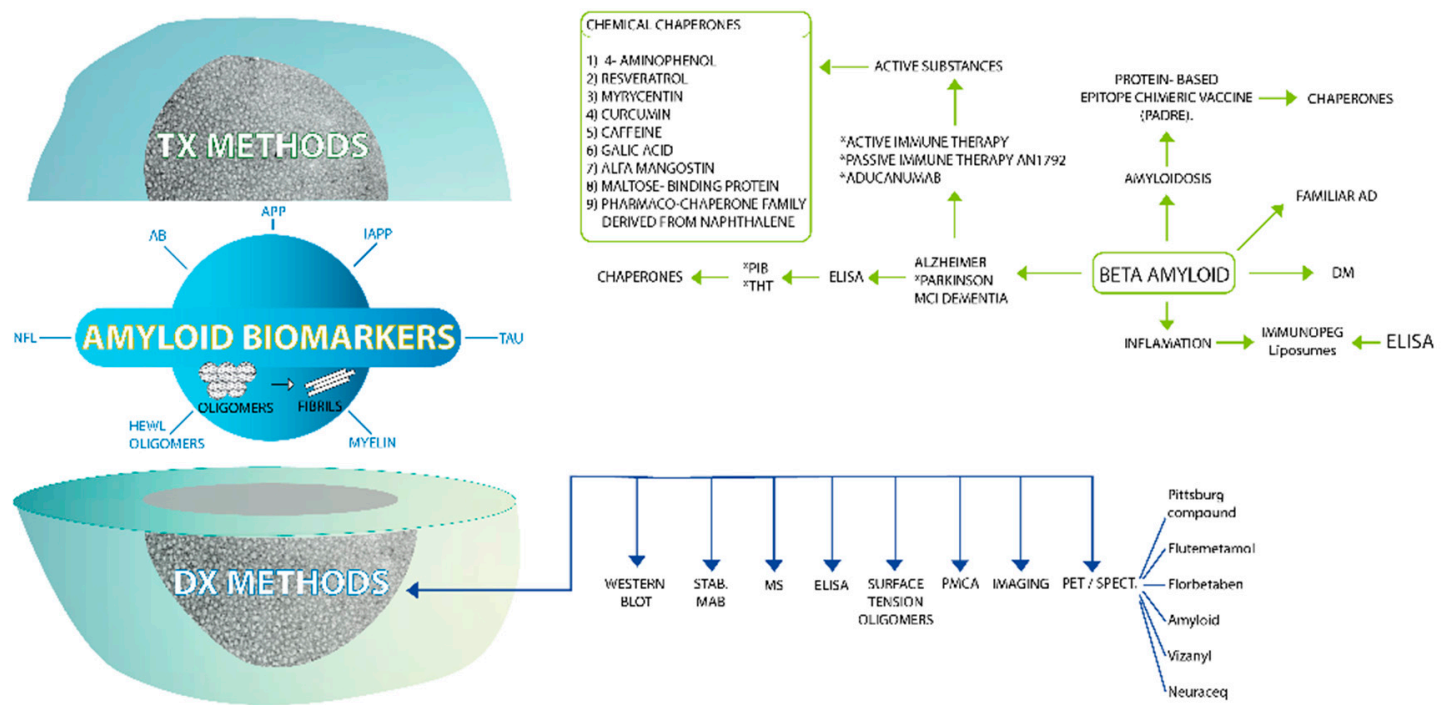

Figure 3. Amyloid biomarkers as target molecules for diagnostic methods and therapeutic approaches in conformational diseases. If we open the amyloid biomarker nucleus we will find several polymorphic amyloid molecules of different target proteins such as APP, AB, amylin, etc. These polymorphic amyloid molecules lead developing actions for diagnostic methods such immunoassays (ELISA, WB, immunodot, etc.), PET/SPECT with several reagents. In relation of multi-target therapeutic drugs, the main explored therapeutic approach is the use of chemical chaperones.

In 1992 Read et al. studied one of the first biomarkers: APP. It competes with the beta Tau protein, also an early biomarker for effective AD diagnosis [42]. It is important to mention that the most common method used is ELISA, and, as can be seen from the studies, a statistical analysis of correlation is required in order to evaluate the validity of biomarkers.

However, these biomarkers are usually not entirely helpful in the diagnosis of AD. This means that the biomarker is not the only element affecting the results, as other factors such as the tissue samples used for amyloid oligomer measurement affect the detection of these molecules (i.e., blood, cerebrospinal fluid, and brain tissue) [40]. However, it has been proven that, in patients with AD, $\mathrm{A} \beta$ and $\beta$-tau protein levels are higher than APP or A $\beta 42$ in CSF, which is why these levels are used as a biomarker of $\mathrm{AD}$ [34]. Other studies support this conclusion: a longitudinal multicenter study with 196 mild congnitive impairment (MCI) patients, 37 of whom developed AD had these A $\beta 42$ and T-tau levels. This study had a sensitivity of $89 \%$ for MCI casas with progression to AD [40] (Table 2, Figures 3-5).

Similarly, a longitudinal MCI-control study in patients with AD proved that low CSF AB42 and high CSF T-tau is a characteristic of AD patients. What's interesting about this study is that the sensitivity was almost $88 \%$ and had a specificity of $80 \%$, making the CSF-B-amyloid levels measured with ELISA a very sensitive diagnostic marker [39]. In the Zetterberg et al. study, a sensitivity of $68 \%$ and a specificity of $97 \%$ was reported, using sample biomarkers. The positive predictive value in other studies reached $94 \%$ and a negative predictive value of $81 \%$ [86]. Other studies that support this diagnostic method have used ELISA to detect $\beta$-amyloid protein in CSF and T-tau [51-54]. 


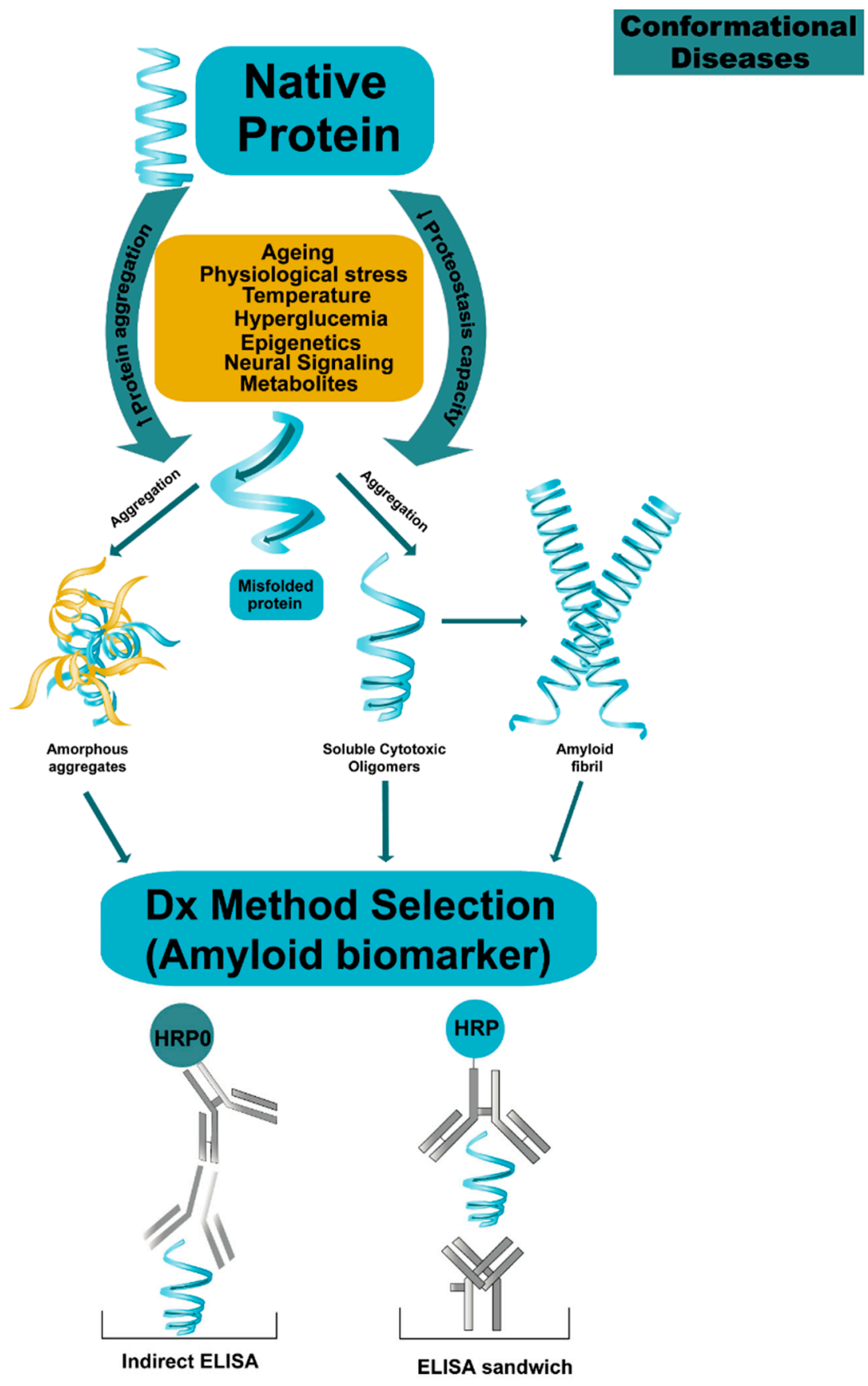

Figure 4. Proposal mechanism on protein aggregation in conformational diseases. The proteins lose their native state by multidimentional factors such as ageing, epigenetic, etc., which produce proteostasis collapsed by increasing protein aggregation and decreasing the capacity for proteostasis. Monomers can self-aggregate and form cytotoxic oligomers leading to self-aggregation or hetero-association and finally the formation of fibrils. The process is dynamic, the oligomeric species become a multi-target molecules for early diagnostic and treatment and the challenge is to claim and stabilize them. 


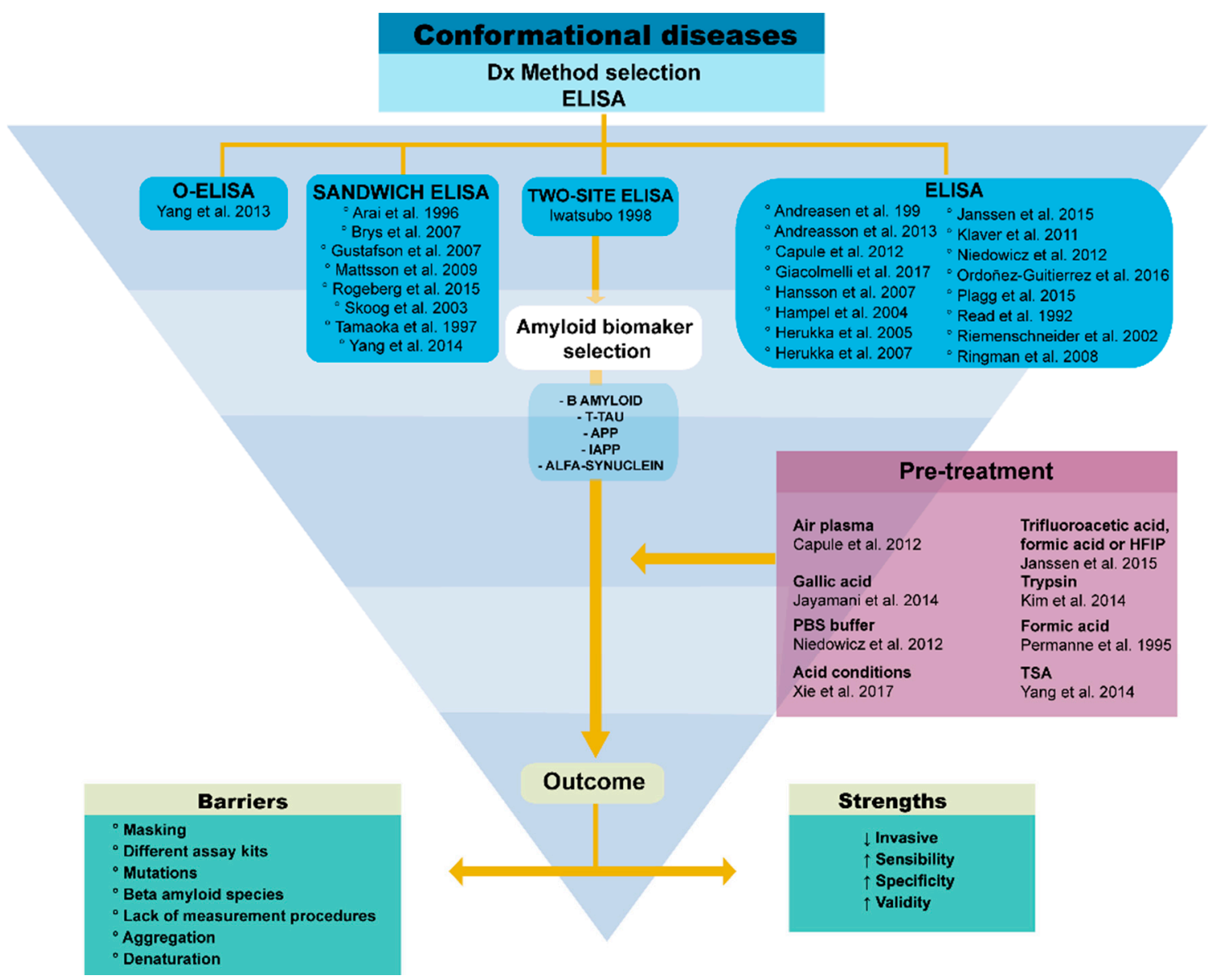

Figure 5. The ELISA challenges and evolving solutions. We show the strengths and limitations of this immunoassay and the pre-treatment possibilities to overcome the limitations.

The most important finding is that this protein can illustrate the pathological changes of AD using only this molecule as a biomarker [69]. Even though there are a great variety of biomarkers, there are still novel ideas on where these amyloid oligomers can be measured. One example is platelets in mutated mice [68]. Another example of biomarker used is the T-tau/A $\beta 42$ ratio. In a longitudinal control study 43 controls were assessed with Luminex reagents and four of these developed MCI. Abnormal levels of this ratio were found in adults over 53 years old. Moreover, controls had increased frequency of the e4 allele of the apolipoprotein E gene and increased risk of progression to MCI. This study was useful in order to give patients a risk-benefit analysis, in order to prevent further onset of MCI and dementia [62] (Table 2, Figures 3 and 4).

A 2-year longitudinal study examined five commonly used CSF biomarkers (isoprostane (IP), T-tau, P-tau, A $\beta 42$, and A $\beta 40$ ) for AD in a study of healthy controls, stable MCI and MCI patients who later had AD. In all initial measurements and follow-up measurements of these biomarkers most of the patients with stable MCI and MCI had an evident decline of CSF biomarkers. P-tau and T-tau were the strongest biomarkers and those with less variability. This information adds to the biomarker dilemma. Moreover, this could also make scientists question which are the most convenient biomarkers to use in control and AD patients [45].

This dilemma has some other implications. In some research, the measurement of $\beta$-amyloid proteins 42 and 40 are one of the most reliable biomarkers for AD, but not for serum amyloid protein samples, according to Iwatsubo et al. [28] and Klaver et al. [60] Some of the barriers include the "masking" of the oligomers when, while binding to an antibody, they lose signal. Moreover, most of the time there are not enough samples in order to perform all the necessary tests. More importantly, 
laboratories use different methods for ELISA immunoassay, and sometimes different assay kits (Figures 3 and 4). Part of the biomarker use comes from the $\beta$ APP have a mutation located in the amino $(\mathrm{N})$ - and $\mathrm{C}$-flanking regions of the $\mathrm{A} \beta$ domain and increase the secretion of total $A \beta$ or the ratio of $A \beta 42$. These results prompted researchers to examine if the levels of $A \beta$, especially those of $A \beta 42$, which are altered in the plasma of patients with AD, including carriers of APP717 (Val to Ile) mutation that is linked to familial AD. A similar study with genetic mutations performed by Ringman et al., was used to study biomarkers and how these can be applied to the diagnosis of presymptomatic diseases. Some of the conclusions were that A $\beta 42$ is elevated in plasma, specifically in familial Alzheimer's disease (FAD) mutation carriers, and this level can decrease with disease progression. The ratio of $A \beta 42$ to $A \beta 40$ was reduced in the CSF of non-demented MCs and the elevation of T-tau and P-tau are sensitive indicators of presymptomatic disease [70] (Figures 3-5, Table 2).

These results can be used for the biochemical diagnosis or classification of subtypes of AD. One of the limitations for amyloid oligomer measurement is the presence of a mutation, therefore, methods are needed in order to identify or discriminate between different types of $\beta$-amyloid species [28]. Another important factor is the considerable overlap of CSF-A $\beta 42$ values when compared between patients with $\mathrm{AD}$ and controls. Sometimes the disease's stage and amyloid oligomer species can affect the detecting ranges and the values themselves [81]. Some ELISA assays have detected different forms of APP including secreted APP forms [68]. Sometimes these results can cause confusion in the results' reading (Figures 3 and 4, Table 2). In our group we have demonstrated that the rat IAPP hexamers are diagnostic biomarkers of the onset and progression of diabetes mellitus and play a role as therapeutic targets $[20,22]$.

\subsection{Technique Challenges and Their Evolving Solutions}

Even though the study of $\beta$-amyloid seems complicated, scientists have developed different techniques to measure and use them as diagnostic information. For example, the most common techniques are immunoassays, imaging, and histological methods. Immunoassays are methods of special interest since they are low cost and less invasive. ELISA can detect protein concentrations due to a series of exposures to antibodies without the use of radioactivity or fluorescent properties. However, this method has a lot of variabilities and some limitations. One limitation is the lack of a reference measurement procedure (RMP) [35]. Another limitation is "antibody masking" which prevents complete antibody measurement by ELISA [60]. Nevertheless, new ELISA techniques are being developed to make the process more efficient and capable of detecting different types of molecules [36]. For instance, competitive ELISA prevents the denaturation of $\beta$-amyloid protein-a very common problem (Figures 3-5).

Another example is the formulation of a pre-treatment protocol to prevent aggregation of amyloid $\beta$-protein. The result is a greater amount of measurable A $\beta$ [56]. Also, techniques like, "two-site" ELISA, are a new trend. In this technique the same antibody is used with a specific sequence for uptake and detection [65]. Another new technique is the use of antibodies using STAB-MAb bound to PEGylated liposomes [32]. Some new protocols for o-ELISA have been developed for soluble oligomers for $\beta$-amyloid protein in the human brain. This is proof that the use of immunoassays is a great tool to identify biomarkers for $\mathrm{AD}$ and at the same time identify the distinct species of $\beta$-amyloid proteins. This method is interesting because of the use of different antibodies [84] (Figures 4 and 5).

Another technique used as an alternative to other methods that require sample handling, several washes and showed increasing inaccuracies and long working times is HTRF [47]. One of the new methods for diagnosis is the use of Positron Emission Tomography (PET) and single-photon emission computed tomography (SPECT). These methods use biomarkers based on fluorescent molecules such as thioflavin T (ThT), the Pittsburgh compound B (PiB) [66], flutemetamol and fluorbetaben [48]. However, only three have been approved by the FDA in the United States: Amyvid ${ }^{\mathrm{TM}}$, Vizamyl ${ }^{\mathrm{TM}}$ and Neuraceq ${ }^{\mathrm{TM}}$ [33]. The problem with these methods is their specificity, or lack thereof since fibres, myelin and neurofibrillary tangles (NFT) are marked along with the molecules relevant to diagnosis. 
For this reason, it is important to perform analyses for different types of amyloid deposits [67]. Within this type of measuring method, selected reaction monitoring mass spectrometry (MS) is also used [59]. Sometimes the sample collecting in CSF are invasive and costly, for this reason researchers have chosen to find reliable and low-cost biomarkers in plasma, monocytes, and platelets [68] (Table 2, Figures 3-5).

Techniques such as mass spectrometry have also been used in conjunction with immunoassays. However, they don't present great advantages [59,71]. Methods for determination of A $\beta$ protein deposition are Bodian or Bielschowsky. Both of these, along with neuropathological studies, have a high correlation when compared with immunoassays. This proves that immunoassays are an effective diagnostic technique [67]. The measurement of surface tension oligomers is also a new trend; it identifies the hydrophobic properties of the amyloid and aggregate rHL fibers. This technique is non-invasive and works well with highly diluted solutions. It is believed that changes in proteins are due to variation in insulin hydrophobicity [73]. One of the limitations is that the oligomers of the amyloid $\beta$-protein have the same structure as the native $A \beta$ protein. For this reason, studies aim to obtain the poorly folded form. For this reason, techniques like protein misfolding cyclic amplification (PMCA) have been developed [74] (Table 2, Figures 3-5).

Despite the different studies, there are still doubts about the reliability of $\beta$-amyloid in CSF and serum as a biomarker [81]. Researches have studied the relationship between the A $\beta$ protein and oligomer levels and different stages of Alzheimer's disease (AD). Within these investigations there is also the study of a possible AD treatment. For example, peripheral administration of anti-6A 15-T serum antibodies mitigated AD-like pathology and cognitive decline of aged $3 \times \mathrm{Tg}-\mathrm{AD}$ mice with passive immunization. This intervention also effectively reduced the levels of the most toxic form of amyloid for neurons: soluble oligomers. Passive immunization significantly reduced the insoluble amyloid and plaque load in the brains of $3 \times \mathrm{Tg}$-AD mice. Antibodies generated or administered in AD model animals or clinical trials have been shown to reduce amyloid deposits in the brains. This could be measured by western blot, immunodot and ELISA [38]. Another possible treatment is trechostatin, also explored with western blotting and binding to $\beta$-amyloid protein [85].

This information provides a perspective in how important the diagnosis of $\beta$-amyloid deposits in human tissues is. Moreover, finding a treatment and low-cost intervention for different patients with AD would also be beneficial. However, the different analyses used to measure the protein interest are still being revised and standardized. For this revision, only the immunoassay ELISA was analysed, since it is one of most cost-effective methods (Table 2, Figures 4 and 5).

As already mentioned, the different uses of ELISA techniques can affect the biomarker values for measurement. In the past, most of the diagnostic techniques used clinical methods, having approximately an 88-90\% accuracy. ELISA immunoassays are trying to compete with these values for diagnosis. Due to this, there are some pre-treatment implications and methodological components that need to be taken into account, for instance, the uniformity of lab and measurement results is a barrier despite the fact that in some of the latest results there is a constant specificity and sensitivity of the ELISA assays from almost 90\%. These results are very optimistic; however, these need to ensure longitudinal consistency. Similar studies report having a big variability between and within laboratories 10-15\% [40] (Figures 4 and 5).

Another consideration is that ELISAs are designed for monomer detection [56,84], but sometimes these monomers tend to aggregate and affect the measurement ranges of the ELISA. In addition, the sensitivity to detect natural oligomers is not well established. Alternative methods like western blot, usually need denaturation to see the peptides and this could decompose oligomers into monomers [84] which this is not a desired practice (Figures 4 and 5).

Antibodies are used in ELISA in order to identify the protein of interest. The antibodies used are a potential problem. When the antibodies are added to the substrate, the anti-A $\beta$ antibodies bind to serum $A \beta$, which can reduce ELISA detection of these antibodies. In some of the experiments, the use of anti-A $\beta$ with different affinities and $K$ constant has been criticized, but the results confirm that the use of these antibodies have nothing to do with the different concentration results [60]. The use of 
different ELISA kits is a big factor for biomarker measurement results [40] because the measuring range can vary. One example is the use of Human Amyloid $\beta$ (1-x), which has specific characteristics and different forms of application to an ELISA protocol. Another example is the IBL International Assay Kit, which has a detection range between 7.81 and $500 \mathrm{pg} / \mathrm{mL}$ and can detect $A \beta$ forms of various lengths, ranging from 28 to 42 amino acids, provided they show no $N$-terminal modification. The cross reactivity with $N$-terminally reported modified A $\beta$ amounts to $0.1 \%[56,68]$ (Table 2, Figures 4 and 5).

New techniques try to overcome the binding-antibody problem in relation to materials used for ELISA and pre-treatment. In the same way other possible pre-treatments are the use of acid (trifluoroacetic acid (TFA), formic acid (FA), and hexafluoroisopropanol (HFIP)). In one experimental report, this was first done with synthetic $\mathrm{A} \beta$ monomer and then with biological brain extract of APP23 mouse model for AD and human cerebrospinal fluid of AD patients and control individuals. These three groups showed minimal deviation $(<10 \%)$ from the theoretical standard concentration, demonstrating no adverse effect on the samples [36] (Table 2, Figure 3).

ELISA is the more cost-effective technique. Some of the reasons are that it doesn't need a very large number of personnel. One person can perform the pre-treatment and the final measurement of oligomers. The most important equipment is the UV-reader, which can be installed in any laboratory. Moreover, the general ELISA protocol is very simple. Technicians do not need any personalized or specialized training for this assay, but not only the protocol elements should be revised for $\beta$-amyloid measurements. Oligomerization of $A \beta$ can lead to epitope masking and steric hindrance, which can result in an underestimation of the $A \beta$ concentration in ELISA analysis. Reconstitution in phosphate-buffered saline (PBS), TFA, HFIP or FA is one of the possible pre-treatment techniques that can solve this problem. Different tests have proved that the best solution for pre-treatment is $1 \% \mathrm{NH}_{4} \mathrm{OH}$ [56] (Table 2, Figures 4 and 5).

There are some protocols where the assay can selectively measure natural $A \beta$ oligomers of various sizes. Two o-ELISA, validated its specificity for oligomeric $A \beta$ and then showed their utility when applied to human and mouse brain tissues [84]. These ELISAs can selectively quantify synthetic and natural oligomers of human $A \beta$ over a wide analytical range. Moreover, they selectively quantify brain $\mathrm{A} \beta$ oligomers from dimers up to much larger assemblies, but cannot detect monomers. The o-ELISAs revealed 1000-fold more oligomers than monomers in the AD cortex and documented the rise in Ab oligomers in APP mouse brain with age. CSF gave no o-ELISA signal, suggesting that the hydrophobicity of oligomers makes them very low or absent in aqueous fluids (Table 2, Figure 3).

\subsection{Polymorphic Amyloid Structures Implications}

Even when the protocols and the use of different biomarkers for $\beta$-amyloid oligomers have been investigated, the biochemical implications play an important role in the disease diagnosis and the performance of ELISA protocols. The secondary structure of the $\beta$-amyloid protein seems to be the one with more interest, since it is the form used for ELISA assays [36]. Moreover, the oligomerization in samples can affect the accuracy of ELISA measurements of the total $\beta$-amyloid protein [56]. This may have a similar effect to amyloid aggregation as a barrier for oligomer measurements. For this reason, the different species of the $A \beta$ protein need different modifications in the measurement techniques [66]. This represents a difficulty, since not all laboratories have the material and equipment to discriminate between the different molecules.

The use of chemicals could have an impact on the biological samples; however, it has been observed that some of the most important factors are the drying times and reconstituting the samples, rather than the chemical itself [56]. If the times of drying are too long, it is likely that the protein of interest denaturizes and thus, the concentration results could be altered.

In the same study performed by Brys et al., a set of five of the most common biomarkers were used to identify the levels of these biomarkers in relation to the onset of AD. One of the interesting findings was that these studies were able to tell which biochemical composition of CSF reflected the $\mathrm{AD}$ pathology. For example, some of the characteristics observed were the neurofibrillary tangles, 
amyloid plaques, and oxidative damage to neuronal cell membranes [45]. In addition to this, the sensitivity and specificity of the measured biomarkers were almost $80 \%$, which can give a clue to which biomarker is better to use in order for early AD diagnosis.

\subsection{Multi-Target Therapeutic Approaches}

ELISAs have been used in the investigation field for a long time. However, with new technologies there is more use of imaging for $\beta$-amyloid aggregation diagnosis. Some of the agents used are PiB, ThT, which need ELISAs in order to quantify the binding of these agents with the $\beta$-amyloid oligomers. These methods tend to be more expensive than immunoassays. What could really benefit patients? One example is that treatment could be possible if measurement ranges are standardized for all patients and for the different AD stages and age [40]. Moreover, the early prediction of Alzheimer's onset would really benefit patients before the symptoms appear. A population-based longitudinal cohort study supports this idea. In said study, 35 non-demented 85-year-old adults underwent a LP and were followed for 3 years. The results show that low CSF AB42 levels were correlated with predicted progression towards dementia [77]. A similar study was conducted by Herukka et al., the difference was that some of the patients in the study had already been diagnosed with Alzheimer's disease [55]. Moreover, abnormal values at baseline have higher risk of developing AD $[44,50,80]$.

Scientists are testing a number of strategies to block the effects of $\beta$-amyloid. Several drugs targeting $\beta$-amyloid have reached human clinical trials. Until the successful aducanumab trial published in 2016, there was no clear indication that these drugs moderated brain changes brought about by Alzheimer's or protected brain cells. Aducanumab, an antibody that binds to both insoluble forms of $\beta$-amyloid (amyloid plaques) and soluble forms, reduced levels of $\beta$-amyloid in the brain and slowed the rate of cognitive decline in a group of people who had mild or preclinical Alzheimer's disease [13]. Active and passive immunotherapy may limit cerebral $\mathrm{A} \beta$ deposition or accelerate its clearance. Another technique used in a clinical trial were the monoclonal anti-A $\beta$ antibody used to construct immune-PEG-liposomes in order to capture $A \beta$ in the peripheries. The role of ELISA here was very important. ELISA was used to test affinity to STAB-Mab for A $\beta$ peptides, to see if the immune-PEG-liposome bind to the protein of interest [32] (Figure 3).

In another clinical study, ELISA was used to measure the initial levels of $\mathrm{A} \beta$ protein in brain and the levels after the treatment. Recently, in the preparation of a protein-based epitope chimeric vaccine using six copies of A $\beta 1-15$ fused with the pan HLA DR-binding peptide (PADRE), generated an adequate anti-A $\beta 42$ antibody response and provided a protective effect in $\mathrm{AD}$ model mice. It also possessed the therapeutic potency of inhibiting $A \beta 42$ oligomer-induced neurotoxicity. Later the efficacy of passive immunization with the $A \beta 42$ oligomer conformation-sensitive serum antibodies in $3 \times \mathrm{Tg}$-AD mice after epitope mapping of serum antibodies was evaluated and characterized [38]. These sensitive and specific ELISAs can be used in quantitative biochemical pathology to correlate oligomeric forms of $A \beta$ for mechanistic analyses and further fluid biomarker searches [84] (Figures 3-5).

Previous attempts at therapeutic intervention in AD focused on reducing the levels of brain $A \beta$ by using antibodies against $A \beta$ or by passive immunization with anti- $A \beta$ antibody. Antibodies' experiments suggested that antibodies against $A \beta$ can modulate the transfer of $A \beta$ between the brain and plasma. Therefore, compounds that can bind to $A \beta$ in the periphery without penetrating blood brain barrier may be ideal candidates as effective therapeutic agents for AD. One such candidate is gelsolin of $90 \mathrm{kDa}$ protein, which is present as a circulating and also an intracellular protein [85].

Recently our research group identified a meta-structure called meta-pharmacophore, which allows the development of novel drugs [22]. We described a pharmaco-chaperone family derived from naphthalene which can do a variety of things: some either accelerate or inhibit the protein-aggregation process (depending on their concentration level), some stabilize the native conformer, some stabilize fibres, and other bind to oligomers accelerating fibre formation. The pharmaco-chaperones act as modulators that provide dynamic interventions and the multi-target capacity required to meet the treatment challenges of conformational diseases [22]. 


\section{Discussion}

Just like the progression of $\mathrm{AD}$, the progression of conformational diseases is an important topic for global health. Because amyloid $\beta$-protein deposition begins to accumulate in obese patients' hearts and in the early stages of insulin resistance [25], it is important to seek timely treatment. Although there are still questions about whether $\beta$-amyloid protein can be used as a biomarker, there are studies that prove that it can serve that purpose. These questions can arise due to the type of screening method chosen or the combination of neurodegenerative diseases. Likewise, the results of $A \beta$ quantification are very different. Some of the possible reasons are the barrier between blood and brain (BBB), the inability to measure the oligomeric form of the $\beta$-amyloid or the use of inappropriate antibodies in the protocols of ELISA [33] (Figure 4).

This systematic review includes 51 articles (Figure 2). Since the method of analysis is very important to identify the different biomarkers, we examined the different methods in all articles. For us, the Receiver Operating Characteristic (ROC) analysis was very important since it reports the sensibility and sensitivity values of the different methods. However, the articles which cited a ROC curve were $4 \%$ of all articles. Moreover, some articles promised better results in a specific method of analysis. Almost $15 \%$ of the articles talked about pre-treatment. $2 \%$ of the articles mentioned air plasma pre-treatment, the same applies to hexafluoroisopropanol and trifluoroacetic acid, gallic acid $2 \%$, trypsin $2 \%$, PBS buffer $2 \%$, formic acid $4 \%$, acid conditions $2 \%$, and TSA $2 \%$ (Table 2, Figures 3 and 4). Similarly, the ELISA analysis method was of particular importance to us and we found that almost $51 \%$ of the articles used ELISA to diagnose and measure the relevant biomarkers. These include: ELISA, single-analyte ELISA, sandwich ELISA, and two-site ELISA (Figures 4 and 5, Table 2).

The biomarker dilemma is multidimensional and encompasses the need for a deep understanding of the aggregation/oligomerization process, their dynamic and their molecule networks (Figure 4). The challenge is to combine methodologies in order to explore the process of oligomerization and the co-aggregation network. The biophysical techniques such as electron microscopy, atomic force microscopy absorbance, fluorescence, Circular dichroism (CD), small-angle X-ray scattering and mass spectrometry have illustrated the structural features of the oligomeric species. For instance, we now know that the soluble amyloid oligomers-the most cytotoxic and the cause of death of target cells (in the brain, pancreas, etc.)—of conformational diseases are characterized by [11,15]:

(a) Low Molecular weight (trimers (10-15 kDa), hexamers (24-30 kDa) [20].

(b) Contain $\beta$-sheet-rich structures [6,11].

(c) Have similar immunogenic reactivities regardless of the target protein $[11,15,87]$.

(d) Strong cytotoxicity [11,15].

(e) Can be formed by monomers (protein misfolding) or by fibril structures halting self-catalysis $[1,88]$.

(f) The anti-amyloid oligomer antibody (A11) distinguishes them [11,15].

(g) Can be monitored by TEM or AFM [15]

This means that a way to overcome the biomarker dilemma while avoiding the polymorphism of oligomeric species is to concentrate on those oligomers with low molecular weight that are related to cellular apoptosis and may have a role to play in the developing stages of conformational diseases.

It is widely acknowledged that one of the most important factors to have a homogeneous population of soluble oligomers is to start with completely solvated stock solutions that lack fibril seeds using, for instance, trifluoroacetic acid $\mathrm{NaOH}$ or fluorinated alcohols. Low $\mathrm{pH}(\mathrm{pH} 2.5-4)$ and low ionic strength is also generally useful. One general means of stabilizing the oligomers after they have been formed is to add $\mathrm{NH}_{4} \mathrm{OH}$ to a final concentration of $0.1 \%$, (final $\mathrm{pH}$ 9.5-10.5). Brief sonication of the stock solutions for $30 \mathrm{~s}$ can serve to disperse and homogenize the samples [87].

In order for these conditions to be used with biological samples (serum, plasma, cerebrospinal fluid, etc.) there would have to be a way to universalise the pre-treatment, this would make it easier to 
get homogenous population of soluble oligomers. This pre-treatment would have to be cost-effective and easy to implement in diagnostic laboratories in hospitals.

The universalization of pre-treatments could potentially solve the ELISAs' limitations as well as those of newer technologies such as electrochemical or optic biosensors.

Since PET studies were complimentary to the immunoassays analysis, the percentage of articles that cited the use of PET and SPECT were almost a $4 \%$ of the selected articles (Figure 3 and Table 2). Spectroscopic methods also played an important function in the research, since they are a new wave in the $\beta$-amyloid and Alzheimer's disease intervention, $45 \%$ of the articles used for this study mentioned that they used a spectroscopic method. These include: Elecsys $\beta$-amyloid assay, Congo Red, fluorescent microscopy, thioflavin T, UV-visible spectroscopy, CD, AFM, FTIR, MS, TEM, SEC, Nile Red, MRI, single photon emission, computed tomography, and MMSE, being thioflavin T the most common one used (Table 2).

Even though ELISA had some preference in the study, some other articles cited using other immunoassays like western blot, innotest, innotest hTau-Ag, immunodot, homogeneous time-resolved fluorescence (HTRF), dot blot, XMAP, immunoprecipitations, multiples, immunoblot, and immunofluorescence microscopy. These accounted for almost $64 \%$ of all articles (Table 2). Lastly, genetic tests were used in other articles. These are almost the $4 \%$ of all articles used for this review. Some examples of these were PCR and PMCA.

Some of the clinical studies that have sought treatment have postulated a number of molecules capable of inhibiting $\beta$-amyloid protein. Small molecules like 4 -aminophenol, resveratrol, myricetin, curcumin, caffeine, and immunization therapy AN1792 [33], are examples of possible treatment options. Gallic acid [57] and $\alpha$-mangostin [38] have also been investigated for the same purpose. Other treatment alternatives are the chaperones which are expressed in situations of stress. This treatment has been shown to have positive effects on the pathogenesis of Alzheimer's disease. Similar treatments like the use of the protein maltose binding protein (MBP) which is believed to have chaperone-like functions [63] (Table 2).

Other suggested treatment options include immunization. There are two types: Active and passive. Active immunization is much more cost-effective since a reduction of oligomers is evident, thanks to the development of more than 600 monoclonal anti-A $\beta$ antibodies which destroy $\beta$-amyloid epitopes [32]. Some of them are A11, OC, Aapf, Anti-ADDL, Anti-ASPD, anti-globulomer and Gammabody [65]. These include the immunotherapeutic drug solanezumab [11], which identifies monomers and non-oligomers or fibres. However, this has a greater affinity to oligomers. This will have a great impact on achieving more precise diagnoses in ELISAs. Immunization with the A $\beta 42$ oligomer conformation-sensitive serum antibodies, inhibits A $\beta 42$ oligomer-mediated neurotoxicity in vitro, was effective in mitigate AD-like pathology and cognitive decline in $3 \times \mathrm{Tg}$-AD mice in vivo. This test has proven to be highly efficient in mice [38] (Table 2 and Figure 3).

In addition to the postulated treatments, it is important to mention that the investigation of molecules that prevent interaction and instability of the mitochondrial membrane by poorly folded species have considered the polyphenols with the help of curcumin, quercetin and resveratrol [72]. Another possible treatment is the administration of PTI-125. This already provided in triple-transgenic $\mathrm{AD}$ mice [38]. However, with this review it is important to mention that induced metal ions and A-BSA/A-HSA —as inhibitor of $\beta$-amyloid aggregation—are considered to be a potential, safe strategy for AD treatment. Yet, this method is still controversial [30] (Figure 3).

Recently our group demonstrated a family of pharmaco-chaperones that potentially treats the conformational diseases at various physio-pathological steps. For example, in chronic stage it is better to use chaperone A-D, which stabilizes the native and fibril structures halting self-catalysis. All the pharmaco-chaperones are able to protect and recondition the cerebellar granule cells from the apoptosis produced by the hIAPP20-29 fragment [22] (Figure 3).

The role of amyloid oligomers is multidimentional because they imply that they can be used for study, potentially be a therapeutic target, and relevant in the therapeutic drug monitoring in CDs. 
ELISA has proved to be a reliable, accessible, non-invasive and cost-effective alternative for screening purposes as well as for post-treatment monitoring of several diseases. If we overcome the biomarker dilemma the same assay can be used in clinical trials to help assess the efficacy and adherence of therapy in CDs and give valuable feedback to healthcare personal and patients.

It is hoped that this review could open the door for the development of novel diagnostic methods and therapeutic agents, that will encourage research in reverse engineering and improve the control of the devastating global changes caused by conformational diseases.

\section{Materials and Methods}

A systematic review was carried for this study (Figures 1 and 2) following a series of techniques described in the Participants/Intervention/Comparison/Outcome (PICO) [89] and Preferred Reporting Items for Systematic Reviews and Meta-Analyses (PRISMA) [90] protocols. These documents can be obtained as supplemental files. No ethical approval or letter of individual consent was required for this research.

\subsection{Data Sources and Searches}

The electronic databases used were PubMed, Embase and BVsalud. The search process started on June 2017 and came to an end in August 2017. According to the PICO methodology (Figure 1), the terms used to perform the search within these databases were:

- P (participants): Humans, animals, Alzheimer, Diabetes Mellitus, conformational diseases, amyloid oligomers, amyloid- $\beta$, oligomers, conformation.

- I Intervention): Immunoassays, Western Blot, Immunodot, ELISA, Enzyme-linked immunosorbent assay, plasma, serum, spreading, blood transmission.

- C (comparison): Method comparison and cost-effectiveness.

- (outcome): Diagnostic methods, diagnostic kit, diagnostic, treatment, therapy.

The concepts with similarity were searched with 'OR' and within the groups of each element of the PICO research, they were searched with the word 'AND'. Next, a diagram was constructed in order to show the history of searches and concepts used (Figure 1). This figure describes in full detail the searching strategy in the PubMed database as well as all the key words used. Moreover, it includes the number of resulting articles. Subsequently, the results obtained from these searches were recorded in a Word document. The references themselves were then downloaded onto the Mendeley database.

\subsection{Eligibility Criteria}

In order to obtain the most relevant results, the selection process of the articles that would be taken into account was divided into three groups (Figure 2). The first round of selection consisted of discarding certain articles based on the type of document; for instance, if the documents were letters or conference notes they were discarded. The documents that predated 1989 were also discarded as well as those articles that were found to be irrelevant to the topic upon reading the abstract. The resulting references were individually downloaded in PDF format and stored in preparation for the second stage of the selection process.

\subsection{Data Extraction and Quality Assessment}

We evaluated all the papers from the first selection step, according to the following points: The articles to be taken into consideration had to have clear objectives and research questions, definitions of the concepts to be measured, valid and reliable measuring instruments, a detailed description of the method, information on the size and type of the target population, information on the number and characteristics of the subjects participating in the study, analysis of missing values, and adequate statistical analysis [37] (Figure 2). Each requirement was worth 12.5 points and so, each article was 
given a grade out of 100 points. To organize this data, a table with the most relevant information of each article and its score was made. Table 1 includes the author's name and year of publication, place of experiment, population size, population characteristics, experiment design and quality score.

Those articles with a score above 75 points were considered for deeper analysis and are listed in Table 2, which includes setting, target molecule, method of analysis, target population, clinical data, sensibility and specificity and pre-treatment.

\section{Conclusions}

Amyloid- $\beta$ is a protein that still raises many questions in relation to the development of serious diseases like AD and diabetes mellitus. A series of experiments have developed techniques like ELISA, western blot and immunodot, yet these techniques lack uniformity and standardization. Moreover, the sample acquisition results are sometimes costly and invasive. Even though this is true, a series of studies examined in this review confirm the use of $\beta$-amyloid oligomers as a biomarker for the diagnosis of conformational diseases. Alternate techniques like imaging and histological tests have been used, however these are high-cost. For this reason, it is important to continue research in this area, even when treatment opportunities have already been achieved.

Acknowledgments: We are indebted to Edgar Leyva-Garcia from the IMSS for helping with the initial systematic review and his participation in fruitful discussions and Claudia Azuela for the proofreading of the manuscript. We also wish to thank Fabio Salamanca and Cristina Revilla for their support as well as Hans Schall Jauregui and Eleane Carolina Herrera Montejano for final editing. The contributions of Erick Dávalos and Brenda Reyes for the artwork are greatly appreciated. Funding for this study was provided by Mexico's National Council of Science and Technology (CONACYT) SALUD-2010-C02-151942, Institute of Science and Technology of Mexico City (ICYTDF).

Author Contributions: N.F.A.-B. and M.M.A.-B. conceived and designed the research; M.F.A.-V. performed the systematic review; M.F.A.-V., N.F.A.-B. and M.M.A.-B. analyzed the data; M.F.A.-V., N.F.A.-B. and M.M.A.-B. wrote the paper.

Conflicts of Interest: The authors declare no conflict of interest.

\section{References}

1. Eisenberg, D.; Jucker, M. The amyloid state of proteins in human diseases. Cell 2012, 148, 1188-1203. [CrossRef] [PubMed]

2. Chiti, F; Dobson, C.M. Protein Misfolding, Functional Amyloid, and Human Disease. Annu. Rev. Biochem. 2006, 75, 333-366. [CrossRef] [PubMed]

3. Daggett, V.; Fersht, A.R. Protein folding and binding: Moving into unchartered territory. Curr. Opin. Struct. Biol. 2009, 19, 1-2. [CrossRef] [PubMed]

4. Chiti, F.; Dobson, C.M. Amyloid formation by globular proteins under native conditions. Nat. Chem. Biol. 2009, 5, 15-22. [CrossRef] [PubMed]

5. Bemporad, F.; Ramazzotti, M. From the evolution of protein sequences able to resist self-assembly to the prediction of aggregation propensity. Int. Rev. Cell Mol. Biol. 2017, 329, 1-47. [CrossRef] [PubMed]

6. Riek, R.; Eisenberg, D.S. The activities of amyloids from a structural perspective. Nature 2016, 539, 227-235. [CrossRef] [PubMed]

7. Cheng, P.-N.; Liu, C.; Zhao, M.; Eisenberg, D.; Nowick, J.S. Amyloid $\beta$-sheet mimics that antagonize protein aggregation and reduce amyloid toxicity. Nat. Chem. 2012, 4, 927-933. [CrossRef] [PubMed]

8. Soriaga, A.B.; Sangwan, S.; Macdonald, R.; Sawaya, M.R.; Eisenberg, D. Crystal structures of IAPP amyloidogenic segments reveal a novel packing motif of out-of-register beta sheets. J. Phys. Chem. B 2016, 120, 5810-5816. [CrossRef] [PubMed]

9. Bucciantini, M.; Calloni, G.; Chiti, F.; Formigli, L.; Nosi, D.; Dobson, C.M.; Stefani, M. Prefibrillar amyloid protein aggregates share common features of cytotoxicity. J. Biol. Chem. 2004, 279, 31374-31382. [CrossRef] [PubMed]

10. Chiti, F.; Webster, P.; Taddei, N.; Clark, A.; Stefani, M.; Ramponi, G.; Dobson, C.M. Designing conditions for in vitro formation of amyloid protofilaments and fibrils. Proc. Natl. Acad. Sci. USA 1999, 96, 3590-3594. [CrossRef] [PubMed] 
11. Sengupta, U.; Nilson, A.N.; Kayed, R. The role of amyloid- $\beta$ oligomers in toxicity, propagation, and immunotherapy. EBioMedicine 2016, 6, 42-49. [CrossRef] [PubMed]

12. Nicolls, M.R. The clinical and biological relationship between Type II diabetes mellitus and Alzheimer's disease. Curr. Alzheimer Res. 2004, 1, 47-54. [CrossRef] [PubMed]

13. Beta Amyloid Hypothesis. Available online: https://www.alz.org/national/documents/topicsheet_ betaamyloid.pdf (accessed on 20 July 2017).

14. Querfurth, H.W.; LaFerla, F.M. Alzheimer's disease. N. Engl. J. Med. 2010, 362, 329-344. [CrossRef] [PubMed]

15. Kayed, R. Common structure of soluble amyloid oligomers implies common mechanism of pathogenesis. Science 2003, 300, 486-489. [CrossRef] [PubMed]

16. Ghosh, D.; Singh, P.K.; Sahay, S.; Jha, N.N.; Jacob, R.S.; Sen, S.; Kumar, A.; Riek, R.; Maji, S.K. Structure based aggregation studies reveal the presence of helix-rich intermediate during $\alpha$-Synuclein aggregation. Sci. Rep. 2015, 5, 9228. [CrossRef] [PubMed]

17. De Matos, A.M.; de Macedo, M.P.; Rauter, A.P. Bridging Type 2 diabetes and Alzheimer's disease: Assembling the puzzle pieces in the quest for the molecules with therapeutic and preventive potential. Med. Res. Rev. 2017. [CrossRef] [PubMed]

18. Carrell, R.W.; Lomas, D.A. Conformational disease. Lancet 1997, 350, 134-138. [CrossRef]

19. Carrell, R.W. Cell toxicity and conformational disease. Trends Cell Biol. 2005, 15, 574-580. [CrossRef] [PubMed]

20. Leyva-García, E.; Lara-Martínez, R.; Morán-Zanabria, L.; Revilla-Monsalve, C.; Jiménez-García, L.F.; Oviedo, N.; Murata, C.; Garrido-Magaña, E.; Altamirano-Bustamante, N.F.; Altamirano-Bustamante, M.M. Novel insight into streptozotocin-induced diabetic rats from the protein misfolding perspective. Sci. Rep. 2017, 7, 11552. [CrossRef] [PubMed]

21. Kayed, R.; Canto, I.; Breydo, L.; Rasool, S.; Lukacsovich, T.; Wu, J.; Albay Iii, R.; Pensalfini, A.; Yeung, S.; Head, E.; et al. Conformation dependent monoclonal antibodies distinguish different replicating strains or conformers of prefibrillar Ab oligomers. Mol. Neurodegener. 2010, 5, 57. [CrossRef] [PubMed]

22. Sablón-Carrazana, M.; Fernández, I.; Bencomo, A.; Lara-Martínez, R.; Rivera-Marrero, S.; Domínguez, G.; Pérez-Perera, R.; Jiménez-García, L.F.; Altamirano-Bustamante, N.F.; Diaz-Delgado, M.; et al. Drug development in conformational diseases: A novel family of chemical chaperones that bind and stabilise several polymorphic amyloid structures. PLOS ONE 2015, 10, e0135292. [CrossRef] [PubMed]

23. Dobson, C.M. Protein misfolding, evolution and disease. Trends Biochem. 1999, 24, 329-332. [CrossRef]

24. Breydo, L.; Kurouski, D.; Rasool, S.; Milton, S.; Wu, J.W.; Uversky, V.N.; Lednev, I.K.; Glabe, C.G. Structural differences between amyloid beta oligomers. Biochem. Biophys. Res. Commun. 2016, 477, 700-705. [CrossRef] [PubMed]

25. Despa, S.; Margulies, K.B.; Chen, L.; Knowlton, A.A.; Havel, P.J.; Taegtmeyer, H.; Bers, D.M.; Despa, F. Hyperamylinemia contributes to cardiac dysfunction in obesity and diabetes: A study in humans and rats. Circ. Res. 2012, 110, 598-608. [CrossRef] [PubMed]

26. Zhao, H.-L.; Sui, Y.; Guan, J.; He, L.; Gu, X.-M.; Wong, H.K.; Baum, L.; Lai, F.M.M.; Tong, P.C.Y.; Chan, J.C.N. Amyloid oligomers in diabetic and nondiabetic human pancreas. Transl. Res. 2009, 153, 24-32. [CrossRef] [PubMed]

27. Blennow, K.; Dubois, B.; Fagan, A.M.; Lewczuk, P.; de Leon, M.J.; Hampel, H. Clinical utility of cerebrospinal fluid biomarkers in the diagnosis of early Alzheimer's disease. Alzheimer's Dement. 2015, 11, 58-69. [CrossRef] [PubMed]

28. Iwatsubo, T. Amyloid $\beta$ protein in plasma as a diagnostic marker for Alzheimer's disease. Neurobiol. Aging 1998, 19, 161-163. [CrossRef]

29. Kepp, K.P. Alzheimer's disease: How metal ions define $\beta$-amyloid function. Coord. Chem. Rev. 2017. [CrossRef]

30. Xie, B.; Liu, F.; Dong, X.; Wang, Y.; Liu, X.M.; Sun, Y. Modulation effect of acidulated human serum albumin on $\mathrm{Cu}^{2+}$-mediated amyloid $\beta$-protein aggregation and cytotoxicity under a mildly acidic condition. J. Inorg. Biochem. 2017, 171, 67-75. [CrossRef] [PubMed]

31. Bush, A.I.; Williamson, T.G.; Moir, R.D.; Li, Q.-X.; Currie, J.; Small, D.; Rumble, B.; Mönning, U.; Beyreuther, K.; Masters, C.L. Plasma amyloid precursor protein is a marker for alzheimer's disease. Pathology 1992, 24. [CrossRef] 
32. Ordóñez-Gutiérrez, L.; Posado-Fernández, A.; Ahmadvand, D.; Lettiero, B.; Wu, L.; Antón, M.; Flores, O.; Moghimi, S.M.; Wandosell, F. ImmunoPEGliposome-mediated reduction of blood and brain amyloid levels in a mouse model of Alzheimer's disease is restricted to aged animals. Biomaterials 2017, 112, 141-152. [CrossRef] [PubMed]

33. Giacomelli, C.; Daniele, S.; Martini, C. Potential biomarkers and novel pharmacological targets in protein aggregation-related neurodegenerative diseases. Biochem. Pharmacol. 2017, 131, 1-15. [CrossRef] [PubMed]

34. Read, S.; Wagner, S.; Vintners, H.; Tomiyasu, U. Amyloid precursor protein activity in early Alzheimer's disease: Diagnostic and prognostic implications. Neurobiol. Aging 1992, 13. [CrossRef]

35. Bittner, T.; Zetterberg, H.; Teunissen, C.E.; Ostlund, R.E.; Militello, M.; Andreasson, U.; Hubeek, I.; Gibson, D.; Chu, D.C.; Eichenlaub, U.; et al. Technical performance of a novel, fully automated electrochemiluminescence immunoassay for the quantitation of $\beta$-amyloid (1-42) in human cerebrospinal fluid. Alzheimer's Dement. J. Alzheimer's Assoc. 2016, 12, 517-526. [CrossRef] [PubMed]

36. Capule, C.C.; Yang, J. Enzyme-linked immunosorbent assay-based method to quantify the association of small molecules with aggregated amyloid peptides. Anal. Chem. 2012, 84, 1786-1791. [CrossRef] [PubMed]

37. Van Mol, M.M.C.; Kompanje, E.J.O.; Benoit, D.D.; Bakker, J.; Nijkamp, M.D.; Seedat, S. The prevalence of compassion fatigue and burnout among healthcare professionals in intensive care units: A systematic review. PLoS ONE 2015, 10, e0136955. [CrossRef] [PubMed]

38. Wang, H.-C.; Yu, Y.-Z.; Liu, S.; Zhao, M.; Xu, Q. Peripherally administered sera antibodies recognizing amyloid- $\beta$ oligomers mitigate Alzheimer's disease-like pathology and cognitive decline in aged $3 \times \mathrm{Tg}-\mathrm{AD}$ mice. Vaccine 2016, 34, 1758-1766. [CrossRef] [PubMed]

39. Andreasen, N.; Hesse, C.; Davidsson, P.; Minthon, L.; Wallin, A.; Winblad, B.; Vanderstichele, H.; Vanmechelen, E.; Blennow, K. Cerebrospinal fluid beta-amyloid(1-42) in Alzheimer disease: Differences between early- and late-onset Alzheimer disease and stability during the course of disease. Arch. Neurol. 1999, 56, 673-680. [CrossRef] [PubMed]

40. Mattsson, N.; Andreasson, U.; Persson, S.; Carrillo, M.C.; Collins, S.; Chalbot, S.; Cutler, N.; Dufour-Rainfray, D.; Fagan, A.M. CSF biomarker variability in the Alzheimer's Association quality control program. Alzheimer's Dement. 2013, 9, 251-261. [CrossRef] [PubMed]

41. Arai, H.; Terajima, M.; Miura, M.; Higuchi, S.; Takase, S.; Clark, C. Tau in cerebrospinal fluid: A potential diagnostic marker in Alzheimer's diseases. Ann. Neurol. 1995, 38, 649-652. [CrossRef] [PubMed]

42. Arai, H.; Terajima, M.; Miura, M.; Higuchi, S.; Takase, S.; Clark, C.; VM, L.; Trojanowski, J.Q.; Sasaki, H. 666 Microtubule-associated protein Tau in CSF: Implications for a potential diagnostic marker in Alzheimer's Disease. Ann. Neurol. 1996, 17, S166.

43. Benedet, A.L.; Labbe, A.; Lemay, P.; Zimmer, E.R.; Pascoal, T.A.; Mathotaarachchi, S. CSF biomarkers and incipient Alzheimer disease in patients with mild cognitive impairment. Neurobiol. Aging 2017, 6, 643-648. [CrossRef]

44. Bouwman, F.H.; Schoonenboom, S.N.M.; van der Flier, W.M.; van Elk, E.J.; Kok, A.; Barkhof, F.; Blankenstein, M.A.; Scheltens, P. CSF biomarkers and medial temporal lobe atrophy predict dementia in mild cognitive impairment. Neurobiol. Aging 2007, 28, 1070-1074. [CrossRef] [PubMed]

45. Brys, M.; Pirraglia, E.; Rich, K.; Rolstad, S.; Mosconi, L.; Switalski, R.; Glodzik-Sobanska, L.; De Santi, S.; Zinkowski, R.; Mehta, P.; et al. Prediction and longitudinal study of CSF biomarkers in mild cognitive impairment. Neurobiol. Aging 2009, 30, 682-690. [CrossRef] [PubMed]

46. Chetri, G.; Pandey, T.; Chinta, R.; Kumar, A.; Tripathi, T. An improved method for high-level soluble expression and purification of recombinant amyloid. Protein Expr. Purif. 2015, 114, 71-76. [CrossRef] [PubMed]

47. Clarke, E.E.; Shearman, M.S. Quantitation of amyloid-beta peptides in biological milieu using a novel homogeneous time-resolved fluorescence (HTRF) assay. J. Neurosci. Methods 2000, 102, 61-68. [CrossRef]

48. Condello, C.; Stöhr, J. A $\beta$ propagation and strains: Implications for the phenotypic diversity in Alzheimer's disease. Neurobiol. Dis. 2017. [CrossRef] [PubMed]

49. Doran, T.; Gao, Y.; Simanski, S.; McEnaney, P.; Kodadek, T. High affinity binding of conformationally constrained synthetic oligomers to an antigen-specific antibody: Discovery of a diagnostically useful synthetic ligand for murine Type 1 diabetes autoantibodies. Bioorg. Med. Chem. Lett. 2015, 25, 4901-4917. [CrossRef] [PubMed] 
50. Gustafson, D.R.; Skoog, I.; Rosengren, L.; Zetterberg, H.; Blennow, K. Cerebrospinal fluid beta-amyloid 1-42 concentration may predict cognitive decline in older women. J. Neurol. Neurosurg. Psychiatry 2007, 78, 461-464. [CrossRef] [PubMed]

51. Hansson, O.; Zetterberg, H.; Buchhave, P.; Londos, E.; Blennow, K.; Minthon, L. Association between CSF biomarkers and incipient Alzheimer's disease in patients with mild cognitive impairment: A follow-up study. Lancet Neurol. 2006, 5, 228-234. [CrossRef]

52. Hansson, O.; Zetterberg, H.; Buchhave, P.; Andreasson, U.; Londos, E.; Minthon, L.; Blennow, K. Prediction of Alzheimer's disease using the CSF Abeta42/Abeta40 ratio in patients with mild cognitive impairment. Dement. Geriatr. Cogn. Disord. 2007, 23, 316-320. [CrossRef] [PubMed]

53. Hampel, H.; Teipel, S.; Fuchsberger, T.; Andreasen, N.; Wiltfang, J.; Otto, M.; Shen, Y.; Dodel, R.; Du, Y.; Farlow, M.; et al. Value of CSF $\beta$-amyloid 1-42 and tau as predictors of Alzheimer's disease in patients with mild cognitive impairment. Mol. Psychiatry 2004, 9, 705-710. [CrossRef] [PubMed]

54. Herukka, S.-K.; Hallikainen, M.; Soininen, H.; Pirttila, T. CSF Abeta 42 and tau or phosphorylated tau and prediction of progressive mild cognitive impairment. Neurology 2005, 64, 1294-1297. [CrossRef] [PubMed]

55. Herukka, S.-K.; Helisalmi, S.; Hallikainen, M.; Tervo, S.; Soininen, H.; Pirttilä, T. CSF Abeta42, Tau and phosphorylated Tau, APOE epsilon4 allele and MCI type in progressive MCI. Neurobiol. Aging 2007, 28, 507-514. [CrossRef] [PubMed]

56. Janssen, L.; Sobott, F.; De Deyn, P.P.; Van Dam, D. Signal loss due to oligomerization in ELISA analysis of amyloid-beta can be recovered by a novel sample pre-treatment method. MethodsX 2015, 2, 112-123. [CrossRef] [PubMed]

57. Jayamani, J.; Shanmugam, G. Gallic acid, one of the components in many plant tissues, is a potential inhibitor for insulin amyloid fibril formation. Eur. J. Med. Chem. 2014, 85, 352-358. [CrossRef] [PubMed]

58. Khan, S.H.; Kumar, R. Trehalose induced conformational changes in the amyloid- $\beta$ peptide. Pathology 2017, 213, 643-648. [CrossRef] [PubMed]

59. Kim, J.S.; Ahn, H.-S.; Cho, S.M.; Lee, J.E.; Kim, Y.; Lee, C. Detection and quantification of plasma amyloid- $\beta$ by selected reaction monitoring mass spectrometry. Anal. Chim. Acta 2014, 840, 1-9. [CrossRef] [PubMed]

60. Klaver, A.C.; Coffey, M.P.; Smith, L.M.; Bennett, D.A.; Finke, J.M.; Dang, L.; Loeffler, D.A. ELISA measurement of specific non-antigen-bound antibodies to A $\beta 1-42$ monomer and soluble oligomers in sera from Alzheimer's disease, mild cognitively impaired, and noncognitively impaired subjects. J. Neuroinflamm. 2011, 8, 93. [CrossRef] [PubMed]

61. Kuo, C.T.; Chen, Y.L.; Hsu, W.T.; How, S.C.; Cheng, Y.H.; Hsueh, S.S.; Liu, H.S.; Lin, T.H.; Wu, J.W.; Wang, S.S.S. Investigating the effects of erythrosine B on amyloid fibril formation derived from lysozyme. Int. J. Biol. Macromol. 2017, 98, 159-168. [CrossRef] [PubMed]

62. Li, G.; Sokal, I.; Quinn, J.F.; Leverenz, J.B.; Brodey, M.; Schellenberg, G.D.; Kaye, J.A.; Raskind, M.A.; Zhang, J.; Peskind, E.R.; et al. CSF tau/Abeta42 ratio for increased risk of mild cognitive impairment: A follow-up study. Neurology 2007, 69, 631-639. [CrossRef] [PubMed]

63. Mangione, M.R.; Vilasi, S.; Marino, C.; Librizzi, F.; Canale, C.; Spigolon, D.; Bucchieri, F.; Fucarino, A.; Passantino, R.; Cappello, F.; et al. Biochimica et biophysica Acta (BBA)-general subjects. Biochim. Biophys. Acta (BBA) Gen. Subj. 2017, 1861, 2515-2944.

64. Mattsson, N.; Ewers, M.; Rich, K.; Kaiser, E.; Mulugeta, E.; Rose, E. CSF Biomarkers and Incipient Alzheimer Disease. JAMA 2009, 302, 385-393. [CrossRef] [PubMed]

65. Murakami, K. Conformation-specific antibodies to target amyloid $\beta$ oligomers and their application to immunotherapy for Alzheimer's disease. Biosci. Biotechnol. Biochem. 2014, 78, 1293-1305. [CrossRef] [PubMed]

66. Niedowicz, D.M.; Beckett, T.L.; Matveev, S.; Weidner, A.M.; Baig, I.; Kryscio, R.J.; Mendiondo, M.S.; LeVine, H.; Keller, J.N.; Murphy, M.P. Pittsburgh compound B and the postmortem diagnosis of alzheimer disease. Ann. Neurol. 2012, 72, 564-570. [CrossRef] [PubMed]

67. Permanne, B.; Buée, L.; David, J.-P.; Fallet-Bianco, C.; Di Menza, C.; Delacourte, A. Quantitation of Alzheimer's amyloid peptide and identification of related amyloid proteins by dot-blot immunoassay. Brain Res. 1995, 685, 154-162. [CrossRef]

68. Plagg, B.; Marksteiner, J.; Kniewallner, K.M.; Humpel, C. Platelet dysfunction in hypercholesterolemia mice, two Alzheimer's disease mouse models and in human patients with Alzheimer's disease. Biogerontology 2015, 16, 543-558. [CrossRef] [PubMed] 
69. Riemenschneider, M.; Lautenschlager, N.; Wagenpfeil, S.; Diehl, J.; Drzezga, A.; Kurz, A. Cerebrospinal fluid Tau and $\beta$-amyloid 42 proteins identify Alzheimer disease in subjects with mild cognitive impairment. Arch. Neurol. 2002, 59, 1729. [CrossRef] [PubMed]

70. Ringman, J.M.; Younkin, S.G.; Pratico, D.; Seltzer, W.; Cole, G.M.; Geschwind, D.H.; Rodriguez-Agudelo, Y.; Schaffer, B.; Fein, J.; Sokolow, S.; et al. Biochemical markers in persons with preclinical familial Alzheimer disease. Neurology 2008, 71, 85-92. [CrossRef] [PubMed]

71. Rogeberg, M.; Almdahl, I.S.; Wettergreen, M.; Nilsson, L.N.G.; Fladby, T. Isobaric quantification of cerebrospinal fluid amyloid- $\beta$ peptides in Alzheimer's disease: C-terminal truncation relates to early measures of neurodegeneration. J. Proteome Res. 2015, 14, 4834-4843. [CrossRef] [PubMed]

72. Roqanian, S.; Meratan, A.A.; Ahmadian, S.; Shafizadeh, M.; Ghasemi, A.; Karami, L. Polyphenols protect mitochondrial membrane against permeabilization induced by HEWL oligomers: Possible mechanism of action. Int. J. Biol. Macromol. 2017, 103, 709-720. [CrossRef] [PubMed]

73. Ruiz, E.D.; Almada, M.; Burboa, M.G.; Taboada, P.; Mosquera, V.; Valdez, M.A.; Juárez, J. Oligomers, protofibrils and amyloid fibrils from recombinant human lysozyme (rHL): Fibrillation process and cytotoxicity evaluation for ARPE-19 cell line. Coll. Surf. B Biointerfaces 2015, 126, 335-343. [CrossRef] [PubMed]

74. Salvadores, N.; Shahnawaz, M.; Scarpini, E.; Tagliavini, F.; Soto, C. Detection of misfolded A $\beta$ oligomers for sensitive biochemical diagnosis of Alzheimer's disease. Cell Rep. 2014, 7, 261-268. [CrossRef] [PubMed]

75. Sharoar, M.; Shahnawaz, M.; Islam, M.; Ramasamy, V.; Shin, S.; Park, I. The inhibitory effects of Escherichia coli maltose binding protein on $\beta$-amyloid aggregation and cytotoxicity. Arch. Biochem. Biophys. 2013, 538, 41-48. [CrossRef] [PubMed]

76. Shaw, L.M.; Vanderstichele, H.; Knapik-Czajka, M.; Clark, C.M.; Aisen, P.S.; Petersen, R.C.; Blennow, K.; Soares, H.; Simon, A.; Lewczuk, P.; et al. Alzheimer's disease neuroimaging initiative cerebrospinal fluid biomarker signature in Alzheimer's disease neuroimaging initiative subjects. Ann. Neurol. 2009, 65, 403-413. [CrossRef] [PubMed]

77. Skoog, I.; Davidsson, P.; Aevarsson, O.; Vanderstichele, H.; Vanmechelen, E.; Blennow, K. Cerebrospinal fluid beta-amyloid 42 is reduced before the onset of sporadic dementia: A population-based study in 85-year-olds. Dement. Geriatr. Cogn. Disord. 2003, 15, 169-176. [CrossRef] [PubMed]

78. Spiegel, D.M.; Sprague, S.M. Serum amyloid P component: A predictor of clinical beta 2-microglobulin amyloidosis. Am. J. Kidney Dis. 1992, 19, 427-432. [CrossRef]

79. Stern, R.; Trojanowski, J.Q.; Lee, V. Antibodies to the beta-amyloid peptide cross-react with conformational epitopes in human fibrinogen subunits from peripheral blood. FEBS Lett. 1990, 264, 43-47. [PubMed]

80. Stomrud, E.; Hansson, O.; Blennow, K.; Minthon, L.; Londos, E. Cerebrospinal fluid biomarkers predict decline in subjective cognitive function over 3 years in healthy elderly. Dement. Geriatr. Cogn. Disord. 2007, 24, 118-124. [CrossRef] [PubMed]

81. Tamaoka, A.; Sawamura, N.; Fukushima, T.; Shoji, S.; Matsubara, E.; Shoji, M.; Hirai, S.; Furiya, Y.; Endoh, R.; Mori, H. Amyloid $\beta$ protein 42(43) in cerebrospinal fluid of patients with Alzheimer's disease. J. Neurol. Sci. 1997, 148, 41-45. [CrossRef]

82. Wang, Y.; Xia, Z.; Xu, J.-R.; Wang, Y.-X.; Hou, L.-N.; Qiu, Y.; Chen, H.-Z. A-Mangostin, a polyphenolic xanthone derivative from mangosteen, attenuates $\beta$-amyloid oligomers-induced neurotoxicity by inhibiting amyloid aggregation. Neuropharmacology 2012, 871-881. [CrossRef] [PubMed]

83. Wang, H.-Y.; Lee, K.-C.; Pei, Z.; Khan, A.; Bakshi, K.; Burns, L.H. PTI-125 binds and reverses an altered conformation of filamin A to reduce Alzheimer's disease pathogenesis. Neurobiol. Aging 2017, 55, 99-114. [CrossRef] [PubMed]

84. Yang, T.; Hong, S.; O’Malley, T.; Sperling, R.A.; Walsh, D.M.; Selkoe, D.J. New ELISAs with high specificity for soluble oligomers of amyloid $\beta$-protein detect natural $A \beta$ oligomers in human brain but not CSF. Alzheimer's Dement. 2013, 9, 99-112. [CrossRef] [PubMed]

85. Yang, W.; Chauhan, A.; Mehta, S.; Mehta, P.; Gu, F.; Chauhan, V. Trichostatin A increases the levels of plasma gelsolin and amyloid beta-protein in a transgenic mouse model of Alzheimer's disease. Life Sci. 2014, 99, 31-36. [CrossRef] [PubMed]

86. Zetterberg, H.; Wahlund, L.-O.; Blennow, K. Cerebrospinal fluid markers for prediction of Alzheimer's disease. Neurosci. Lett. 2003, 352, 67-69. [CrossRef] [PubMed] 
87. Kayed, R.; Glabe, C.G. Conformation-dependent anti-amyloid oligomer antibodies. Methods Enzym. 2006, 413, 326-344. [CrossRef]

88. Nelson, R.; Sawaya, M.R.; Balbirnie, M.; Madsen, A.Ø.; Riekel, C.; Grothe, R.; Eisenberg, D. Structure of the cross-beta spine of amyloid-like fibrils. Nature 2005, 435, 773-778. [CrossRef] [PubMed]

89. Colegio oficial de enfermeria de málaga. Formulación de preguntas clínicas específicas en formato PICO. Rev. Cuid. Digit. 2013, 5, 2013. Available online: http:/ / revistacuidandote.eu/fileadmin/VOLUMENES/ 2013/Volumen5/Formacion/FORMULACION_DE_PREGUNTAS.....pdf (accessed on 20 July 2017).

90. Liberati, A.; Altman, D.G.; Tetzlaff, J.; Mulrow, C.; Gøtzsche, P.C.; Ioannidis, J.P.A.; Clarke, M.; Devereaux, P.J.; Kleijnen, J.; Moher, D. The PRISMA statement for reporting systematic reviews and meta-analyses of studies that evaluate health care interventions: Explanation and elaboration. PLoS Med. 2009, 6. [CrossRef] [PubMed]

(C) 2017 by the authors. Licensee MDPI, Basel, Switzerland. This article is an open access article distributed under the terms and conditions of the Creative Commons Attribution (CC BY) license (http:/ / creativecommons.org/licenses/by/4.0/). 